Article

\title{
Interfacial Shearing Behavior along Xanthan Gum Biopolymer-Treated Sand and Solid Interfaces and Its Meaning in Geotechnical Engineering Aspects
}

\author{
Minhyeong Lee ${ }^{1}$, Jooyoung Im ${ }^{1}$, Gye-Chun Cho ${ }^{1}{ }^{(D}$, Hee Hwan Ryu ${ }^{2}$ and Ilhan Chang ${ }^{3, * \mathbb{D}}$ \\ 1 Department of Civil and Environmental Engineering, Korea Advanced Institute of Science and \\ Technology (KAIST), Daejeon 34141, Korea; minhyeong@kaist.ac.kr (M.L.); jooyoungim@kaist.ac.kr (J.I.); \\ gyechun@kaist.edu (G.-C.C.) \\ 2 KEPCO Research Institute, Korea Electric Power Corporation (KEPCO), Daejeon 34056, Korea; \\ hhryu82@kepco.co.kr \\ 3 Department of Civil Systems Engineering, Ajou University, Suwon-si 16499, Korea \\ * Correspondence: ilhanchang@ajou.ac.kr; Tel.: +82-31-219-2503
}

Citation: Lee, M.; Im, J.; Cho, G.-C.; Ryu, H.H.; Chang, I. Interfacial Shearing Behavior along Xanthan Gum Biopolymer-Treated Sand and Solid Interfaces and Its Meaning in Geotechnical Engineering Aspects. Appl. Sci. 2021, 11, 139. https:// dx.doi.org/10.3390/app11010139

Received: 9 December 2020

Accepted: 22 December 2020

Published: 25 December 2020

Publisher's Note: MDPI stays neutral with regard to jurisdictional claims in published maps and institutional affiliations.

Copyright: (C) 2020 by the authors. Licensee MDPI, Basel, Switzerland. This article is an open access article distributed under the terms and conditions of the Creative Commons Attribution (CC BY) license (https: / / creativecommons.org/ licenses/by/4.0/).

\begin{abstract}
Recently, environment-friendly microbial biopolymer has been widely applied as a new construction material in geotechnical engineering practices including soil stabilization, slope protection, and ground injection. Biopolymer is known to exhibit substantial improvements in geotechnical properties, such as shear strength enhancement and hydraulic conductivity reduction, through the formation of direct ionic bonds with soil particles, especially clay particles. Moreover, the rheological characteristics (e.g., pseudoplasticity, shear-rate dependent thixotropy) of biopolymers render distinctive behaviors such as shear thinning and lubrication effect under a high strain condition, while recovering their viscosities and shear stiffnesses when they are at rest. To ensure the practical applicability of biopolymer-based soil treatment, it is important to understand the interfacial interaction (i.e., friction) between biopolymer-treated soil and adjoining structural members which can be constructed in a biopolymer-treated ground. Thus, in this paper, interfacial shearing behavior of biopolymer-treated soil along solid surfaces as well as internal shearing on biopolymer-soil matrix were explored via direct and interface shear test. Experimental results show a predominant effect of the soil moisture content on the interfacial shear behavior of biopolymer-treated soil which attributes to the rheology transition of biopolymer hydrogels. At low moisture content, condensed biopolymer biofilm mobilizes strong intergranular bonding, where the interfacial shear mainly depends on the physical condition along the surface including the asperity angle. In contrast, the biopolymer induced intergranular bonding weakens as moisture content increases, where most interfacial failures occur in biopolymer-treated soil itself, regardless of the interface condition. In short, this study provides an overall trend of the interfacial friction angle and adhesion variations of xanthan gum biopolymer-treated sand which could be referred when considering a subsequent structural member construction after a biopolymer-based ground improvement practice in field.
\end{abstract}

Keywords: interface; shear strength; biopolymer; xanthan gum; soil-structure; interface friction angle

\section{Introduction}

Studying the shear behavior at the interface between the exterior surface of solid structures and the surrounding earth material is essential for understanding the soilstructure interaction, which plays an important role in the geotechnical engineering design of various structures including deep foundations, retaining wall structures (e.g., anchored, reinforced, soil nailing), landfills, and slope stability [1]. Thus, interfacial shearing of soil has been investigated by several researchers using various laboratory testing methods such as the interface direct shear, ring shear, simple shear, and resonant-column torsional shear tests [2-6]. The mechanical behavior of soil-solid structure interfaces depends on the 
physical properties of the soil as well as the structural surface characteristics. Among them, the particle shape, which includes angularity and size distribution, surface roughness, cementation, and normal stress, mainly influences the interfacial shearing behavior of soil [7]. Moreover, these factors induce variations in the apparent adhesion and interface friction angle $(\delta)$, which are considered as the main parameters for the design and analysis of the actual soil-structure interaction. In the general design of geotechnical structures having shear resistances or frictional behaviors between soil and solid materials, $\delta$ is considered to be in the range of $1 / 2-2 / 3$ times the internal friction angle $(\phi)$ of soil, and the magnitude of interface adhesion $\left(c_{a}\right)$ is typically considered to be a fraction of the soil cohesion $(c)[8,9]$.

Biopolymers have been recently suggested as environment-friendly soil-stabilizing materials owing to their origin and low greenhouse gas footprint [10-13]. Accordingly, recent research has investigated the feasibility of biopolymer-based soil treatment (BPST) for geotechnical ground improvement practices in terms of soil strengthening and permeability reduction [14-20]. Several studies have assessed the shear strength parameters (i.e., internal friction angle and cohesion) and strengthening efficiency (e.g., unconfined compressive strength) of biopolymer-treated sand through triaxial shear, direct shear, and uniaxial compression test approaches $[14,15,18,21-24]$. Additionally, the shear parameters of BPST exhibit moisture content-dependent characteristics, which are expected to be associated with the rheological properties of biopolymer hydrogels inside the soil. As most biopolymer hydrogels (e.g., xanthan gum, guar gum) are thixotropic, they exhibit a shear thinning characteristic with decreasing viscosity and yield stress with a large strain rate [25]. The rheological characteristics of biopolymer hydrogels could affect the interface shearing behavior between biopolymer-treated soil and structures, when structural members (e.g., piles, geosynthetics) are implemented into biopolymer-treated grounds. Thus, understanding the interaction between biopolymer-treated soil matrix and adjacent structure surfaces becomes crucial for stability analysis and BPST application. Previous studies on BPST have mostly focused on the biopolymer-induced soil strengthening, while there is no research considering the interfacial interaction behavior between biopolymertreated soil and adjoining structural (i.e., solid, non-geomaterial) members reported yet. Hence, in this study, the effects of the moisture state and biopolymer concentration on the internal and interfacial shearing behavior of xanthan gum-treated soil are reported. For this purpose, the mobilization of shear strength and volume change response of both internal and interfacial behaviors of xanthan gum-treated sand were studied via direct (laboratory) and interfacial shear tests according to a wide range of normal stress, moisture state, biopolymer concentration, and interface type conditions.

\section{Materials and Experimental Process}

\subsection{Materials}

2.1.1. Jumunjin Sand

Jumunjin sand is used in this study, which is standard cohesionless sand found in Korea. According to the Unified soil classification system (USCS), it is classified as a poorly graded sand (SP) with an average particle size $\left(D_{50}\right)$ of $0.47 \mathrm{~mm}$ (Figure 1). Detail soil properties of jumunjin sand are listed in Table 1.

Table 1. Properties of sand used in this study.

\begin{tabular}{ccccccc}
\hline $\begin{array}{c}\text { Mean Grain Size } \\
D_{50}[\mathrm{~mm}]\end{array}$ & $\begin{array}{c}\text { Specific } \\
\text { Gravity } \\
\boldsymbol{G}_{\boldsymbol{s}}[-]\end{array}$ & $\begin{array}{c}\text { Coefficient of } \\
\text { Uniformity } \\
\boldsymbol{C}_{\boldsymbol{u}}[-]\end{array}$ & $\begin{array}{c}\text { Coefficient of } \\
\text { Curvature } \\
\boldsymbol{C}_{\boldsymbol{c}}[-]\end{array}$ & $\begin{array}{c}\text { Maximum Void } \\
\text { Ratio } \boldsymbol{e}_{\text {max }}[-]\end{array}$ & $\begin{array}{c}\text { Minimum } \\
\text { Void Ratio } \\
\boldsymbol{e}_{\text {min }}[-]\end{array}$ & $\begin{array}{c}\text { USCS } \\
\text { USP }\end{array}$ \\
\hline 0.47 & 2.65 & 1.12 & 0.98 & 0.95 & 0.644 \\
\hline
\end{tabular}




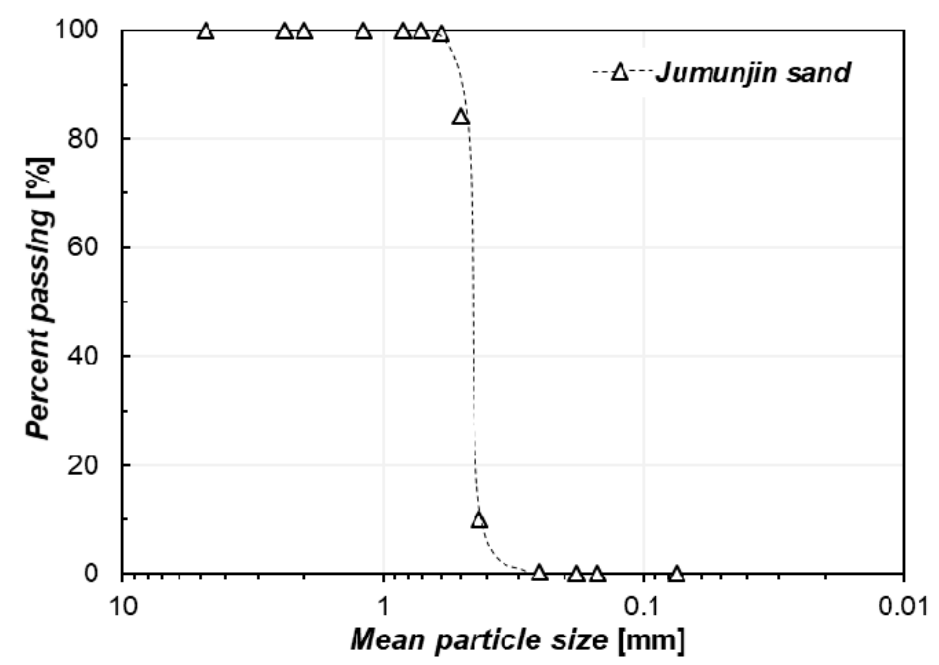

Figure 1. Particle size distribution of jumunjin sand.

\subsubsection{Biopolymer: Xanthan Gum}

In this study, xanthan gum, one of the representative viscous-type biopolymers, is used as the main material. Xanthan gum is a biopolymer widely used in various industries for viscosity thickening and is a polysaccharide created by the Xanthomonas campestris bacterium. The molecular structure of xanthan gum consists of two glucoses, two mannoses, and one glucuronic acid. It presents anionic characteristics owing to which it adsorbs water molecules through hydrogen bonding easily, thereby mainly forming viscous fluids (hydrogel state) [26]. In addition, xanthan gum solution is known as a non-Newtonian fluid which shows shear thinning characteristic. The shear rate dependent viscosity response of three different xanthan gum solutions (i.e., different xanthan gum to water ratio in mass; $M_{x g} / M_{w}$ ) assessed by a rotational rheometer (Kinexus Pro, Malven Instruments) shows reduction in viscosity with shear rate increase (Figure 2), which is anticipated to affect the shearing behavior along the biopolymer-treated soil-structure interface.

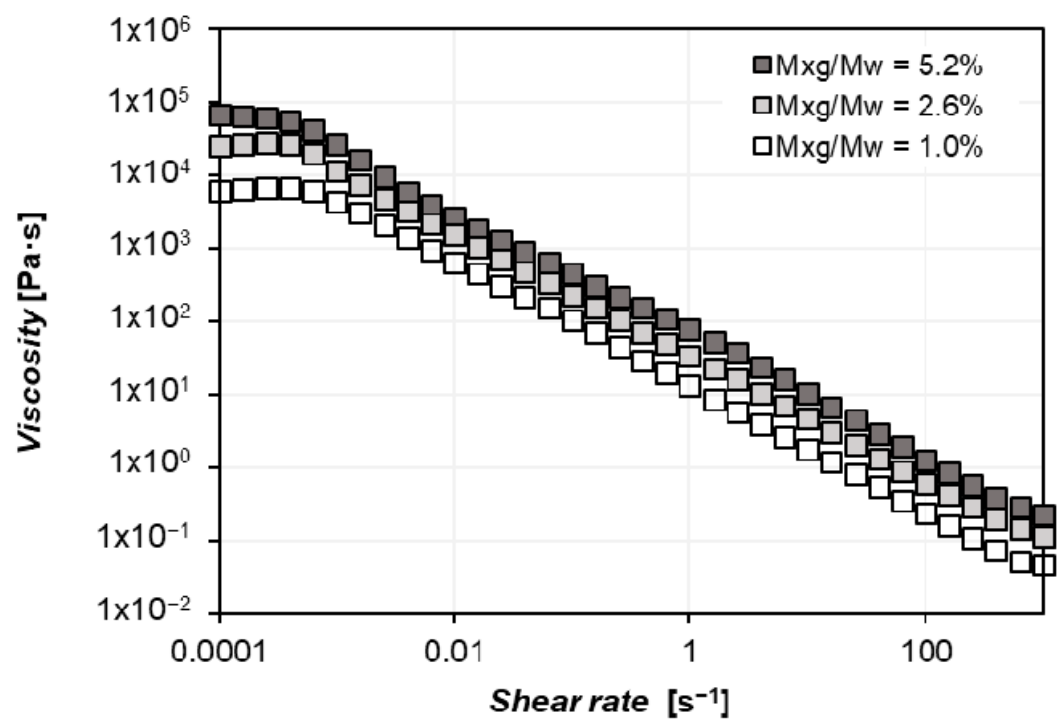

Figure 2. Shear rate dependent viscosity reduction of xanthan gum hydrogels at different xanthan gum to water $\left(M_{x g} / M_{w}\right)$ ratios in mass.

\subsubsection{Interfacial Structure Model}

To represent the structural member for laboratory testing, solid material blocks were fabricated via 3D printing using a polylactide (PLA) filament. The PLA filament is often 
suggested as a geosynthetic bioplastic material that has the advantage of rapid manufacturing and sustainability. $[27,28]$. The interfacial structure model is composed of a single structure without asperity and three other structures having single triangular asperities with tilt angles of $10^{\circ}, 20^{\circ}$, and $30^{\circ}$ (Figure 3a). The interfacial structure was designed with dimensions of $60 \mathrm{~mm}$ diameter and $12.5 \mathrm{~mm}$ height. A $20 \mathrm{~mm}$-wide asperity was carved along the middle axis of the disc, and the tilt angles of the asperity varied from $0^{\circ}$ (no asperity) to $30^{\circ}$, as shown in Figure 3a [29]. The surface roughness of measuring length of 5000 $\mu \mathrm{m}$ for 3D-printed solid structure was evaluated by surface profiler equipment (Dektak-8, Veeco) for $100 \mathrm{~s}$. Uesugi and Kishida (1986) introduced the normalized relative roughness $\left(R_{n}\right)$, which expresses the ratio between the maximum peak-to-valley distance of asperities along the solid surface and the average particle size $\left(D_{50}\right)$ of interacting particulate material as [30]:

$$
R_{n}=\frac{R_{\max }\left(L=D_{50}\right)}{D_{50}} .
$$

The $R_{n}$ between the interfacial structure model (Figure $3 \mathrm{~b}$ ) and jumunjin sand used in this study has been assessed as 0.12 . Meanwhile, literatures report the normalized $R_{n}$ values of materials used in actual geotechnical practices as listed in Table 2 [31-34] and an interface can be defined as smooth $\left(R_{n}<0.02\right)$, rough $\left(R_{n}>0.2\right)$, and intermediate $(0.02 \leq$ $R_{n} \leq 0.2$ ) [35]. Generally, $R_{n}$ exceeds 0.05 for a typical pile surface in practice, and $R_{n}$ used in this study $\left(R_{n}=0.12\right)$ is found competitively to represent common structural members (e.g., medium concrete, $R_{n}=0.12$; rough steel, $R_{n}=0.17$ ) used in geotechnical engineering practices [36]. As the $R_{n}$ along the block surfaces is regarded to be constant $\left(R_{n}=0.12\right)$, a single asperity was added at the middle of the block surface to investigate the asperity effect on the geometric dilation and shear resistance which is an important consideration along solid-solid anomalous interfaces [37].

Table 2. Normalized relative roughness $\left(R_{n}\right)$ used in this study.

\begin{tabular}{ccc}
\hline Interface Condition (Type) & $\boldsymbol{R}_{\boldsymbol{n}}$ in $\mathbf{~ m m}\left(\boldsymbol{D}_{50}\right)$ & References \\
\hline$R_{n}$ in this study & $0.12\left(D_{50}=0.47\right)$ & \\
\hline Very rough steel & $0.43\left(D_{50}=0.65\right)$ & \\
Rough steel & $0.17\left(D_{50}=0.65\right)$ & {$[31]$} \\
Intermediate steel & $0.08\left(D_{50}=0.65\right)$ & \\
Smooth steel & $0.03\left(D_{50}=0.65\right)$ & \\
Brass & $0.03\left(D_{50}=0.65\right)$ & \\
\#120 Sand paper & $0.26\left(D_{50}=0.65\right)$ & \\
\#50 Sand paper & $1.14\left(D_{50}=0.65\right)$ & \\
Smooth concrete & $0.002\left(D_{50}=0.5\right)$ & \\
Medium concrete & $0.12\left(D_{50}=0.5\right)$ & \\
Rough concrete & $0.2\left(D_{50}=0.5\right)$ & \\
\hline Smooth woven geotextile & $0.03\left(D_{50}=0.65\right)$ & \\
Moderately rough woven geotextile & $0.19\left(D_{50}=0.65\right)$ & \\
Rougher woven geotextile & $0.30\left(D_{50}=0.65\right)$ & \\
\hline
\end{tabular}




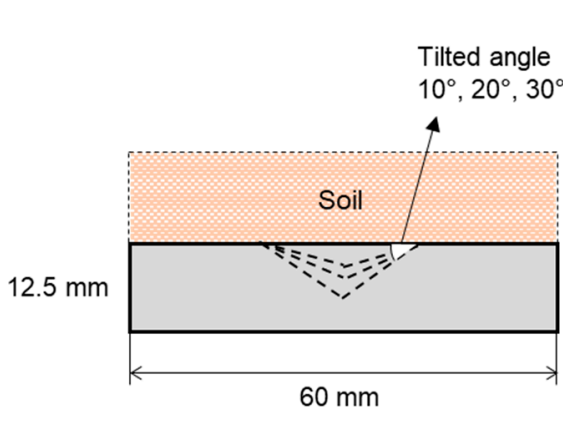

(a)

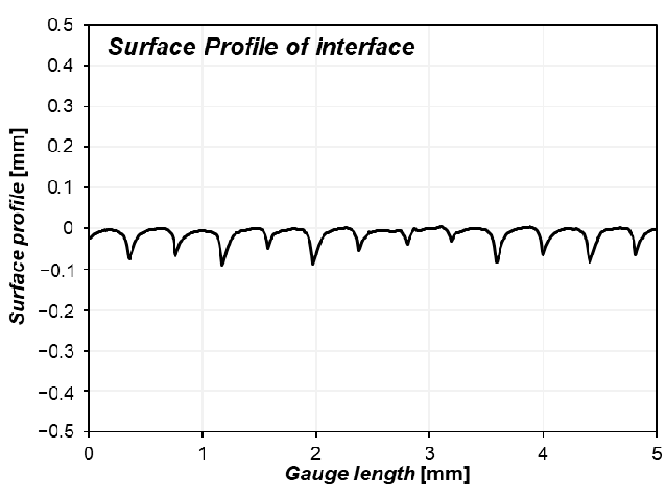

(b)

Figure 3. Structural materials: (a) schematic diagram; (b) typical surface profiles.

\subsection{Experimental Process}

\subsubsection{Specimen Preparation}

The moisture content and xanthan gum concentration (xanthan gum to soil ratio in mass; $M_{X G} / M_{S}$ ) of the specimens used for direct and interface shear tests are listed in Table 3. All the soil and soil-structure samples were first prepared using dry sand and xanthan gum powder (Sigma-Aldrich ${ }^{\circledR}$, CAS number 11138-66-2) with an initial water content (in mass ratio) of $20 \%$. The ratios of xanthan gum mass to that of sand were $0 \%$ (i.e., untreated), $0.5 \%, 1.0 \%$, and $2.0 \%$ (corresponding to $2.5 \%, 5.0 \%$, and $10 \%$ ratios to the mass of water). Purified xanthan gum powder was dissolved in distilled water at room temperature $\left(21^{\circ} \mathrm{C}\right)$, and the mixture was magnetically stirred to obtain a uniform xanthan gum solution (i.e., hydrogel). Once done, the solution was mixed with dry sand, and cylindrical bulk soil and cylindrical soil-structure specimens with dimensions of $60 \mathrm{~mm}$ diameter and $25 \mathrm{~mm}$ height were prepared using a specimen ring for direct shear tests (Figure 3a). The initial dry density of specimens was controlled to fit within $1450 \pm 10 \mathrm{~kg} / \mathrm{m}^{3}$ where the relative density $\left(D_{r}\right)$ of soil showed a range of $36-44 \%$ (medium state), via tapping to minimize the effect of different particle packing density on soil strengthening $[38,39]$. The specimens were prepared for three representative moisture states (i.e., initial, dried, and resubmerged). The initial state indicates when the specimens were tested immediately after preparation (i.e., approximately having $20 \%$ of water content in mass ratio), while dry condition samples were tested after oven-drying the specimens at $40{ }^{\circ} \mathrm{C}$ for 21 days where specimen water content reached less than $3 \%$. The resubmerged samples were prepared by fully immersing the dried samples in deionized water (i.e., water level reached the top of the sample) at room temperature for $24 \mathrm{~h}$ to achieve a condition close to saturation as much as possible [40].

Table 3. Experimental conditions.

\begin{tabular}{lll}
\hline \multicolumn{1}{c}{ Variables } & \multicolumn{1}{c}{ Direct Shear Test } & \multicolumn{1}{c}{ Interface Shear Test } \\
\hline Shearing condition & Soil-soil & Soil-solid structure \\
\hline Moisture state & $\begin{array}{l}\text { Initial state } \\
\text { Dried state } \\
\text { Resubmerged state }\end{array}$ & $\begin{array}{l}\text { Initial state } \\
\text { Dried state } \\
\text { Resubmerged state }\end{array}$ \\
\hline $\begin{array}{l}\text { Xanthan gum concentration } \\
{\left[M_{X G} / M_{S}, \%\right]}\end{array}$ & $0,0.5,1,2$ & $0,0.5,1,2$ \\
\hline $\begin{array}{l}\text { Vertical confinement pressure } \\
{[\mathrm{kPa}]}\end{array}$ & $50,100,200,400$ & $50,100,200,400$ \\
\hline
\end{tabular}




\subsubsection{Direct and Interface Shear Tests}

In this study, direct shear box testing which provides pseudo-strain measurement was used to investigate the internal and interfacial shearing behavior of xanthan gumtreated sand. A series of interface direct shear tests were conducted and compared with the ordinary soil direct shear test (soil-to-soil shearing) results under the same conditions (Table 3). All samples were tested using a direct shear test apparatus (Humboldt HM5750D.3F), as shown in Figure 4. The samples were vertically confined with pressures of $50,100,200$, and $400 \mathrm{kPa}$ by porous stones placed both on top and beneath until the vertical strain reached a stable state before applying the horizontal shear displacement. For each vertical confinement, the horizontal shear was applied with a constant shear rate of $0.6 \mathrm{~mm} / \mathrm{min}(1 \%$ per $\mathrm{min}$ ) for $1000 \mathrm{~s}$ (final horizontal displacement is $10 \mathrm{~mm}$ ) according to the ASTM D3080/D3080M-11 [41]. The horizontal load, vertical displacement, and horizontal displacements were obtained automatically every $10 \mathrm{~s}$ using a load cell and LVDT apparatuses. Both tests were triplicated at all conditions to obtain reliable average values.

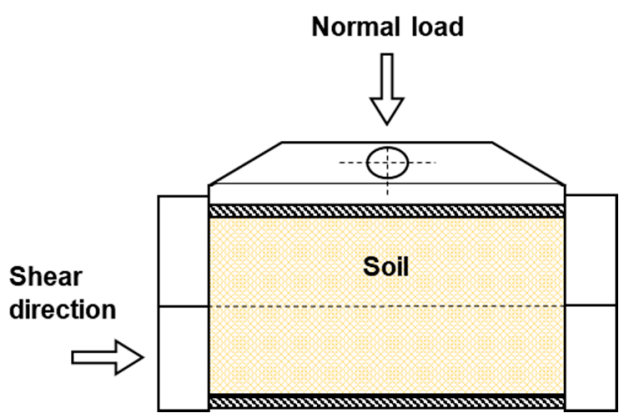

(a)

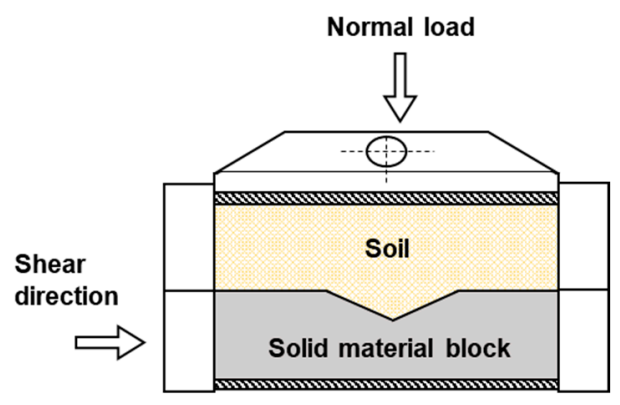

(b)

Figure 4. Schematic diagram of experimental setup: (a) direct shear test; (b) interface shear test.

\section{Results}

\subsection{Shearing Behavior of Xanthan Gum-Treated Sand (Soil-to-Soil Shearing) in Hydrogel State}

The representative direct shear stress $(\tau)$-horizontal displacement $(\delta)$ behavior of xanthan gum-treated sand according to different normal stress, moisture state, and $M_{X G} / M_{S}$ values are presented in Figure 5. The $\tau$ values were calculated by dividing the measured shear force by the effective area of specimens, which is found to decrease along the shearing process, as shown in Figure $5 a, c, e$. The vertical strain $\left(\varepsilon_{v}\right)$ values were calculated as the ratios of vertical displacement in samples to the initial height of samples $(25 \mathrm{~mm})$. Positive values indicate a volumetric dilation, whereas negative values indicate a volumetric contraction. The maximum dilation angle $\left(\psi_{\max }\right)$ under shearing was derived from the largest ratio (i.e., slope) of the vertical and horizontal displacement as shown in Figure 5b,d,f.

Figure $5 \mathrm{a}, \mathrm{b}$ shows the shear behavior of xanthan gum-treated $(1 \%)$ sand using vertical confinement pressures of 50,100, 200, and $400 \mathrm{kPa}$. Overall, the direct shear stress and vertical strain were seen to vary depending on the normal stress. As the normal stress increased, the direct shear stress also increased (Figure 5a), while the soil became less dilative (Figure 5b) owing to the stronger interlocking among sand grains [21].

Figure $5 c$,d presents the shear behavior at three different moisture states (i.e., initial, dried, and resubmerged) of xanthan gum-treated sand. The xanthan gum hydrogel occurring in pore spaces in the sand showed different trends of its strengthening effect depending on the hydraulic state. A phase change in xanthan gum solution from a hydrogel (initial state) to the xanthan gum film occurred with dehydration (dried) [16], which generated tensile strengths. Thus, an obvious peak of the shear strength exists prior to failure followed by a residual strength with more dilation compared to other samples having presence of water. Moreover, the condensed xanthan gum film becomes disturbed and reaches a swollen state when it is exposed to water (resubmerged) and exhibits a more contractive behavior than 
that of uniform hydrogel at the initial state [40]. Figure 5e,f reveals that the direct shear stress of xanthan gum-treated sand increases with the $M_{X G} / M_{S}$ in dried state. Compared to pure sand, xanthan gum-treated sand shows a remarkable strengthening effect and dilation at dried conditions, and this effect is greater at higher $M_{X G} / M_{S}$ conditions, which increases the thickness of xanthan gum films in dried conditions.

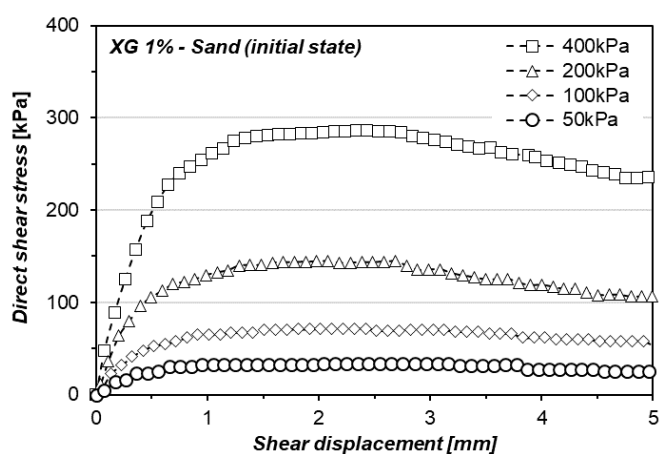

(a)

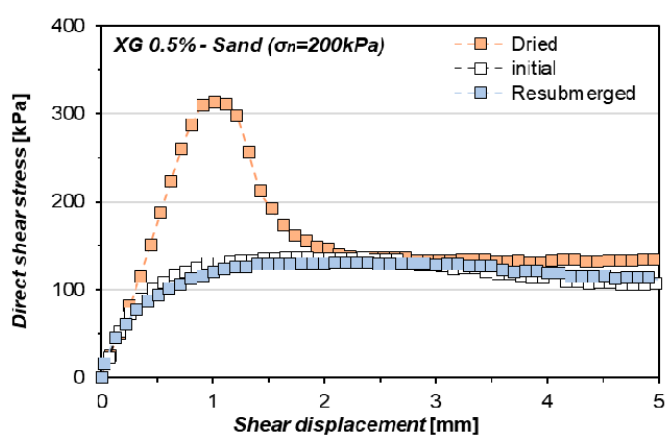

(c)

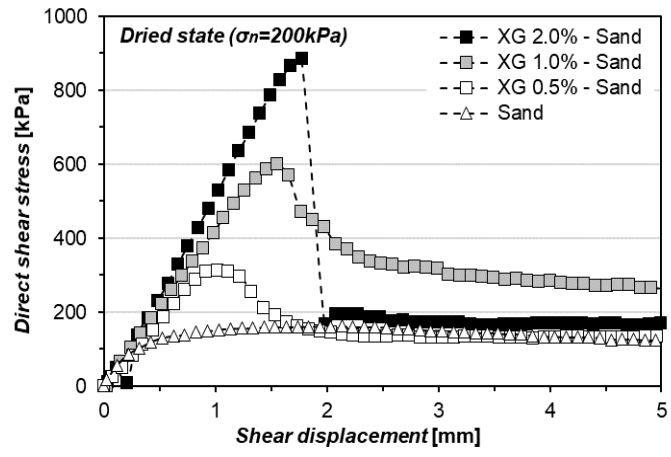

(e)

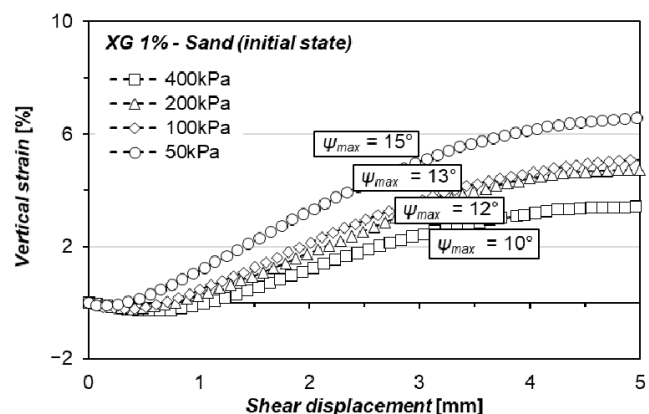

(b)

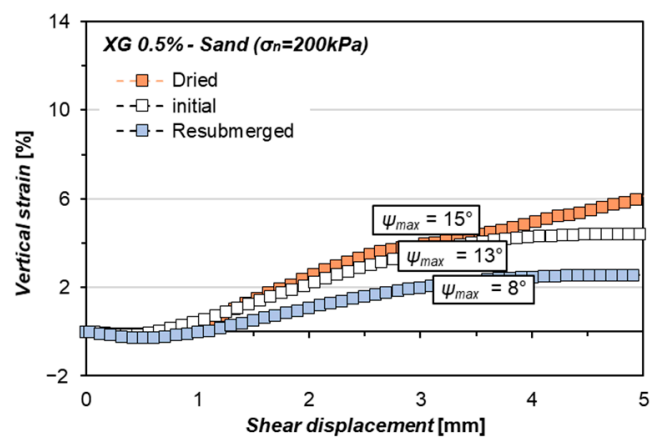

(d)

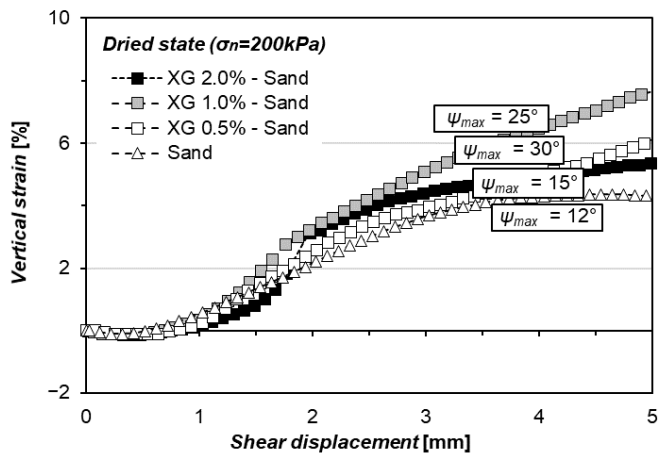

(f)

Figure 5. Direct shear test results of xanthan gum-treated soil: $(\mathbf{a}, \mathbf{c}, \mathbf{e})$ direct shear stress $(\tau)$-horizontal shear displacement $(\delta)$ curves; $(\mathbf{b}, \mathbf{d}, \mathbf{f})$ vertical strain $\left(\varepsilon_{v}\right)$-horizontal shear displacement $(\delta)$ curves.

The Mohr-Coulomb failure envelopes for the peak and residual direct shear strengths of xanthan gum-treated sand with varying moisture states are presented in Figure 6. The shear parameters determined from the linear regression of the failure envelope are listed in Table 4. Generally, both the peak and residual shear strengths linearly increase with an increasing degree of normal stress. The strengthening effect of xanthan gum is rarely observed in its initial state (Figure 6a); however, the cohesion (c) slightly increases the pressure to $23.2 \mathrm{kPa}$ with a decrease of the internal friction angle $\left(\phi=39.0^{\circ}\right.$ to $\left.34.6^{\circ}\right)$ according to $M_{X G} / M_{S}$. The residual strength of xanthan gum-treated sand is found to be lower than that of pure sand (Figure 6b). 
Meanwhile, xanthan gum treatment increases the strength of soil significantly in terms of the internal friction angle and cohesion with $M_{X G} / M_{S}$ increase in the dried state. $c$ is raised to $563.7 \mathrm{kPa}$ with an increment of $\phi$ from $39.0^{\circ}$ to $53.7^{\circ}$ under a condition of $M_{X G} / M_{S}=2 \%$ (Figure 6c). Increase in two shear parameters ( $\phi$ and $c$ ) was also observed in the residual behavior, although the increment efficiency with $M_{X G} / M_{S}$ increase was lower than the peak behavior, especially for c (Figure 6d).

When dried xanthan gum-treated sand is resubmerged, the shear strength tends to be restored to its initial state (Figure 6e,f). However, a higher peak strength is still observed at higher $M_{X G} / M_{S}$ conditions as the swelling occurred was inadequate, while the dried hydrogel with lower $M_{X G} / M_{S}$ was fully swollen, which can be clearly observed under a low confining stress condition.

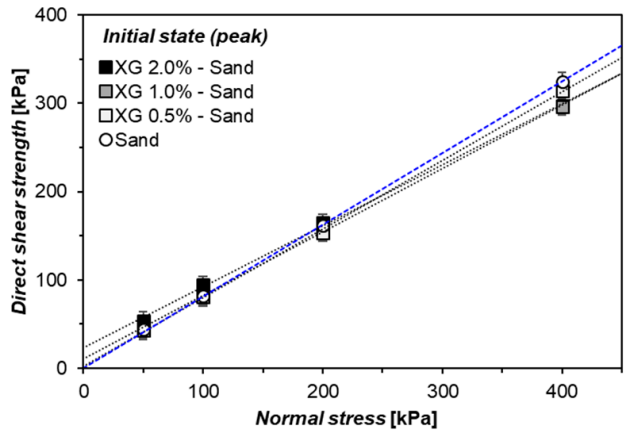

(a)

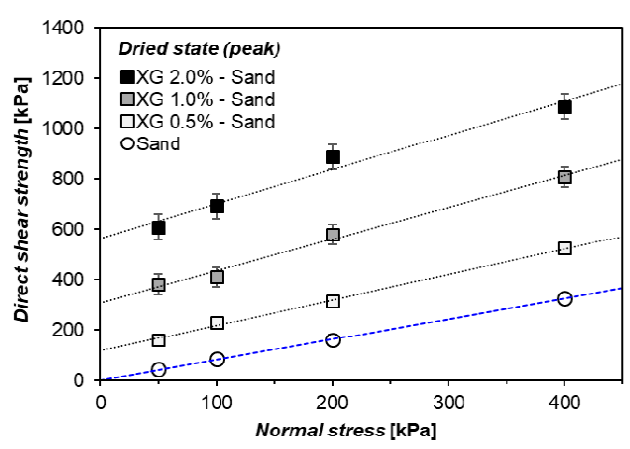

(c)

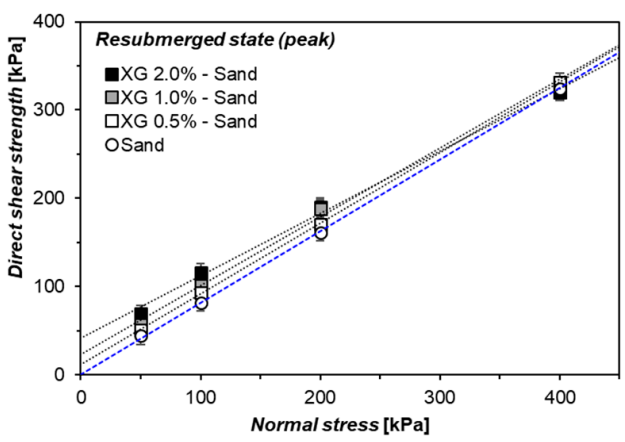

(e)

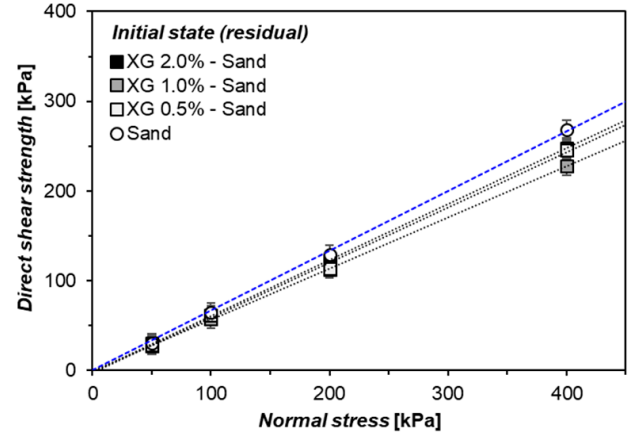

(b)

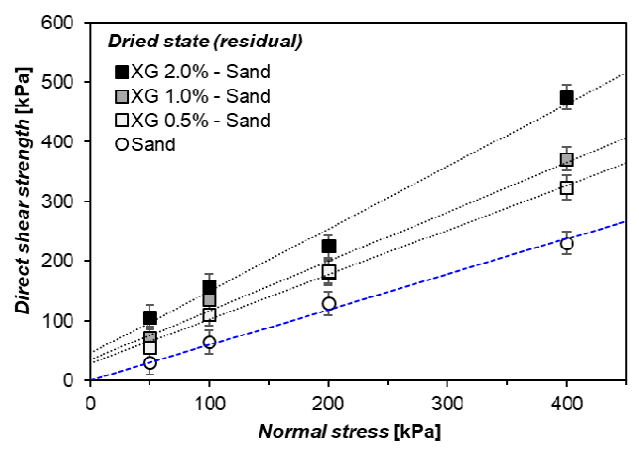

(d)

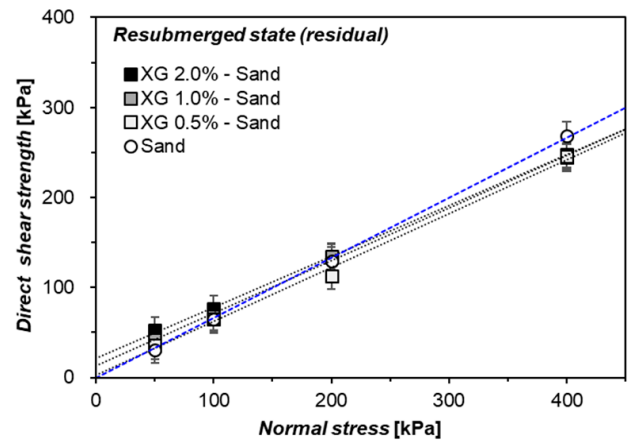

(f)

Figure 6. Peak and residual strength of xanthan gum-treated sand: $(\mathbf{a}, \mathbf{b})$ initial condition; (c,d) dry condition; (e,f) resubmerged condition. 
Table 4. Mohr-Coulomb failure parameters determined from linear regression (soil-soil shearing).

\begin{tabular}{|c|c|c|c|c|c|}
\hline \multirow[b]{2}{*}{ Hydrogel State } & \multirow[b]{2}{*}{$\begin{array}{l}\text { Xanthan Gum } \\
M_{X G} / M_{S}[\%]\end{array}$} & \multicolumn{2}{|c|}{ Peak Strength } & \multicolumn{2}{|c|}{ Residual Strength } \\
\hline & & $\begin{array}{l}\text { Cohesion } \\
\text { [kPa] }\end{array}$ & Friction Angle $\left[{ }^{\circ}\right]$ & $\begin{array}{c}\text { Cohesion } \\
{[\mathrm{kPa}]}\end{array}$ & Friction Angle $\left[{ }^{\circ}\right]$ \\
\hline \multirow{4}{*}{ Initial } & 0.0 & $<1$ & 39.0 & $<1$ & 33.6 \\
\hline & 0.5 & 2.5 & 38.1 & $<1$ & 31.1 \\
\hline & 1.0 & 8.5 & 36.9 & $<1$ & 29.6 \\
\hline & 2.0 & 23.2 & 34.6 & $<1$ & 31.7 \\
\hline \multirow{4}{*}{ Dried (Initial $\rightarrow$ Dried) } & 0.0 & $<1$ & 39.0 & $<1$ & 33.6 \\
\hline & 0.5 & 117.1 & 45.4 & 28.2 & 36.8 \\
\hline & 1.0 & 307.7 & 51.6 & 34.9 & 39.5 \\
\hline & 2.0 & 563.7 & 53.7 & 45.1 & 46.3 \\
\hline \multirow{4}{*}{$\begin{array}{l}\text { Resubmerged (Initial } \rightarrow \text { Dried } \\
\quad \rightarrow \text { Resubmerged) }\end{array}$} & 0.0 & $<1$ & 39.0 & $<1$ & 33.6 \\
\hline & 0.5 & 11.4 & 38.6 & 3.6 & 30.7 \\
\hline & 1.0 & 23.3 & 37.9 & 12.8 & 30.3 \\
\hline & 2.0 & 41.1 & 35.3 & 21.7 & 29.4 \\
\hline
\end{tabular}

\subsection{Xanthan Gum-Treated Sand Shearing at Interface without Asperities (Interface I)}

Results of the interfacial shearing (Interface I) of xanthan gum-treated sand without asperities are presented in Figure 7 . The interface shear stress $\left(\tau_{i}\right)$-horizontal displacement $(\delta)$ curve shows a vertical confinement-dependent behavior similar to the results of the direct shear test with a quite less dilation being the only difference. On the other hand, the shear behavior of initial condition of untreated and xanthan gum-treated sand on interface I exhibits a sliding behavior in which $\tau_{i}$ maintains a constant value along displacement (Figure $7 \mathrm{a}, \mathrm{b}$ ). Moreover, depending on the hydrated state of xanthan gum, a peak and strain-softening behavior is observed when xanthan gum-treated sand is dried, while $\tau_{i}$ is restored to be similar to that of the initial state after exposure to water (i.e., resubmerged state in Figure 7c,d).

Xanthan gum treatment in initial state caused a slight decrease of $\tau_{i}$, but the difference was not remarkably observed depending on the $M_{X G} / M_{S}$ (Figure 7e,f). Xanthan gum in the hydrogel state retains enough moisture due to its hydrophilic property. A slight lubrication effect is generated between the particles and the solid surface due to the pseudoplasticity of xanthan gum hydrogel, resulting in the reduction of the frictional resistance [42]. Meanwhile, dehydration of xanthan gum hydrogel showed increases in $\tau_{i}$ and $\psi_{\max }$ with brittle behavior in which $\tau_{i}$ rapidly decreased after reaching a clear peak failure, and this behavior occurred distinctively with a sequential increase of $M_{X G} / M_{S}$ (Figure $7 \mathrm{~g}, \mathrm{~h}$ ).

The Mohr-Coulomb failure envelopes for peak and residual interfacial shear strengths of xanthan gum-treated sand (Interface I) according to varying moisture states are presented in Figure 8. The shear parameters determined from the linear regression of failure envelope are listed in Table 5. As mentioned above, xanthan gum treatment in the initial state slightly reduces the interface friction angle $(\delta)$ from $28.6^{\circ}$ to $26.7^{\circ}$ regardless of $M_{X G} / M_{S}$ (Figure 8a). Adhesion $\left(c_{a}\right)$ values were found to be less than $3 \mathrm{kPa}$, which indicates little contribution to the peak strengths (Figure $8 \mathrm{~b}$ ) and even for residual strengths at interface I. 


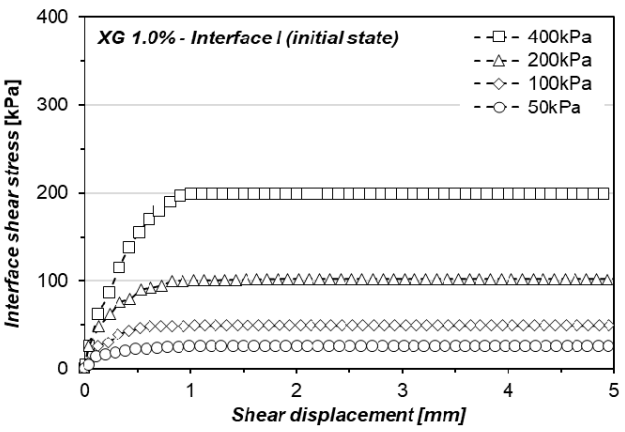

(a)

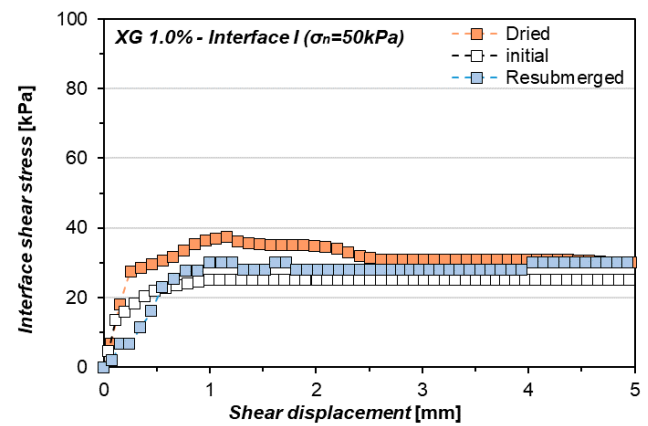

(c)

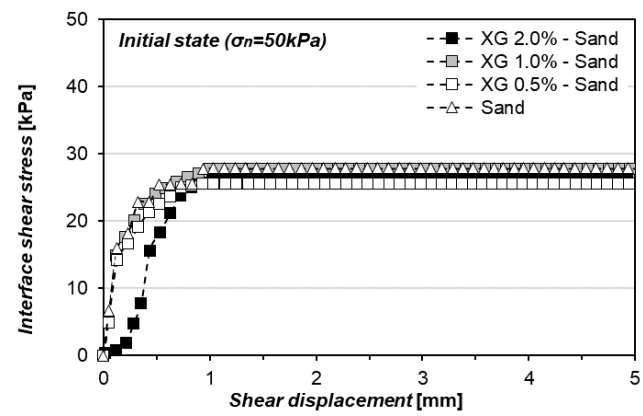

(e)

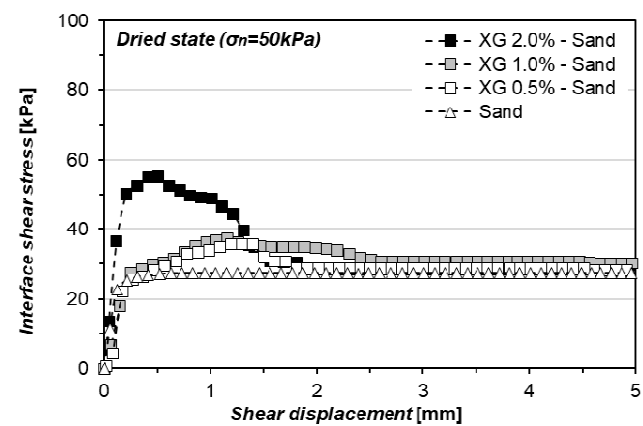

(g)

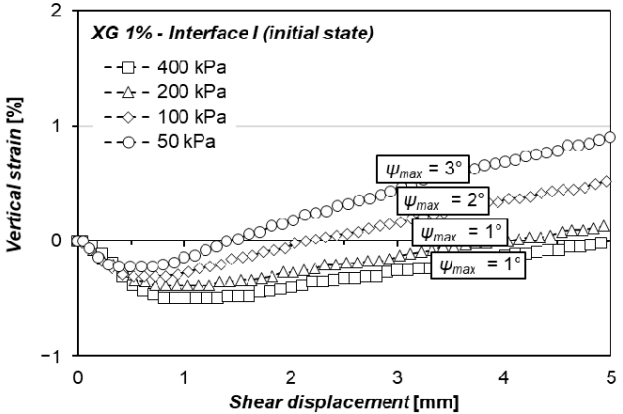

(b)

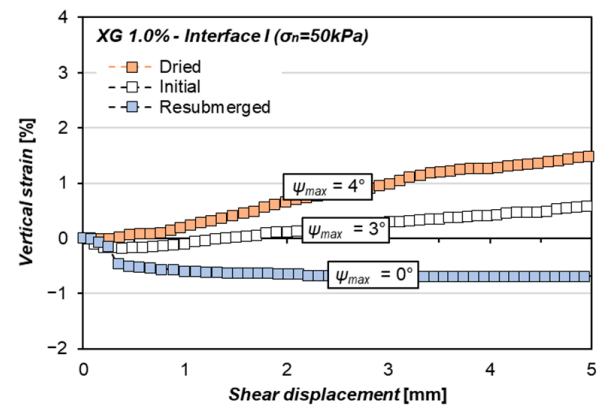

(d)

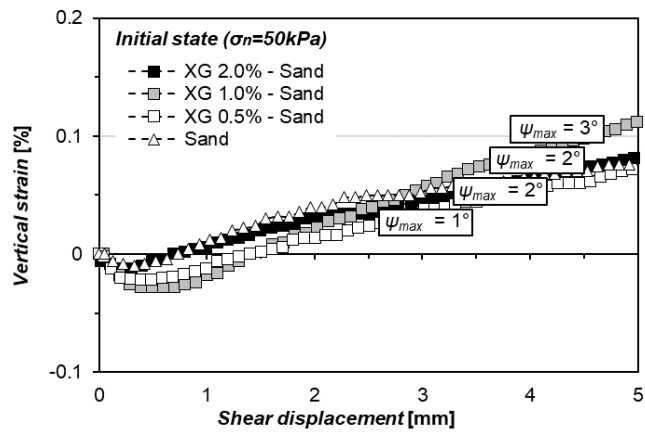

(f)

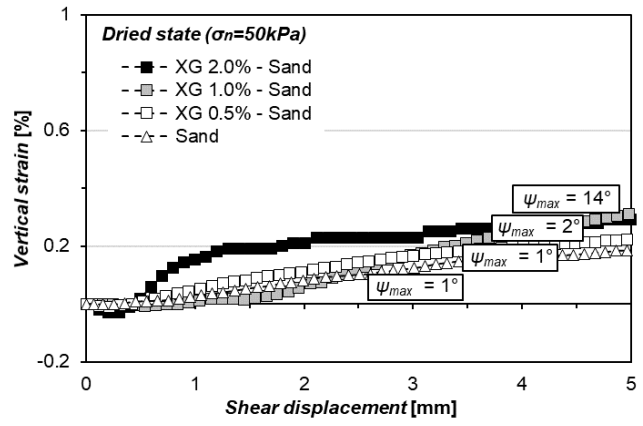

(h)

Figure 7. Interfacial shear test results of xanthan gum-treated soil without asperities (Interface I): (a,c,e,g) interface shear stress $(\tau)$-horizontal shear displacement $(\delta)$ curves; $(\mathbf{b}, \mathbf{d}, \mathbf{f}, \mathbf{h})$ vertical strain $\left(\varepsilon_{v}\right)$-horizontal shear displacement $(\delta)$ curves. 


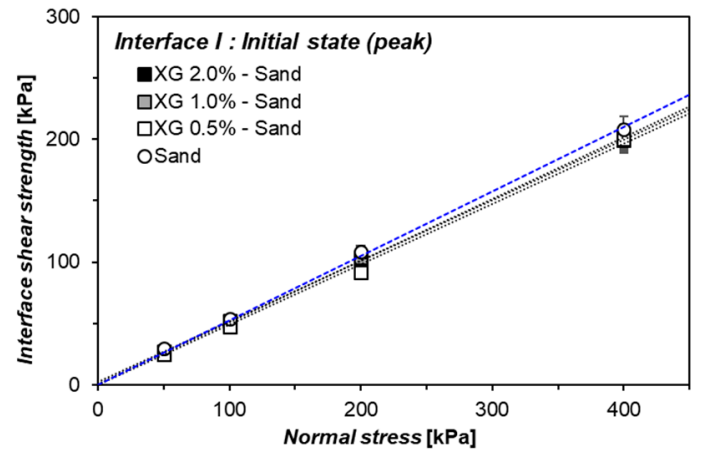

(a)

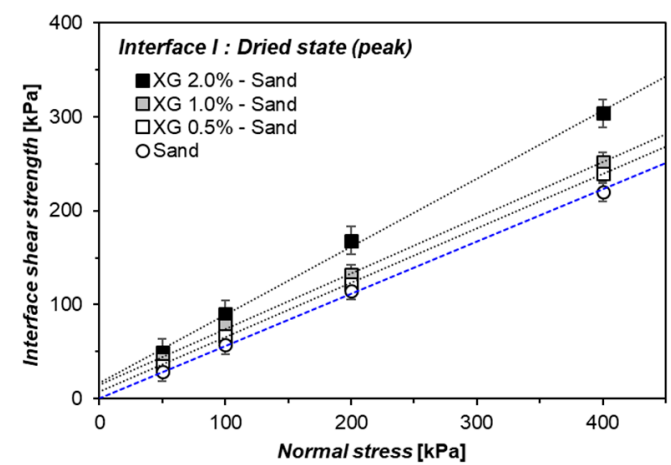

(c)

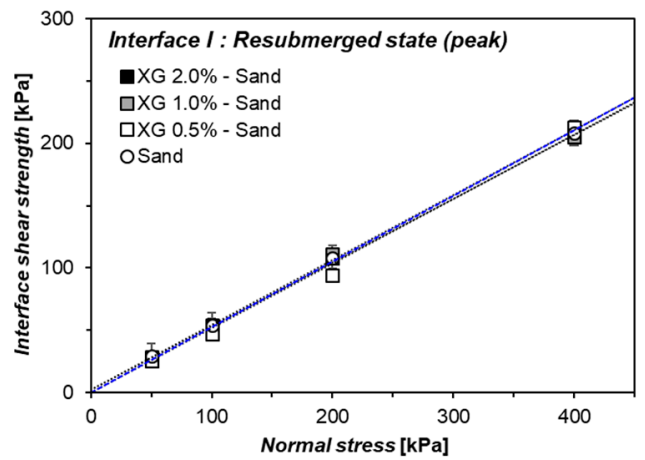

(e)

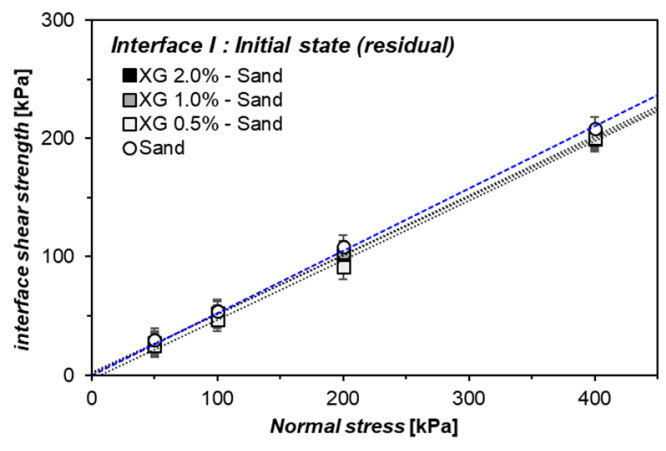

(b)

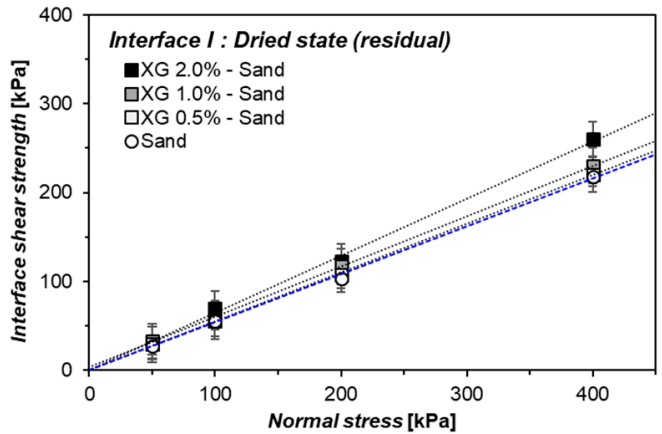

(d)

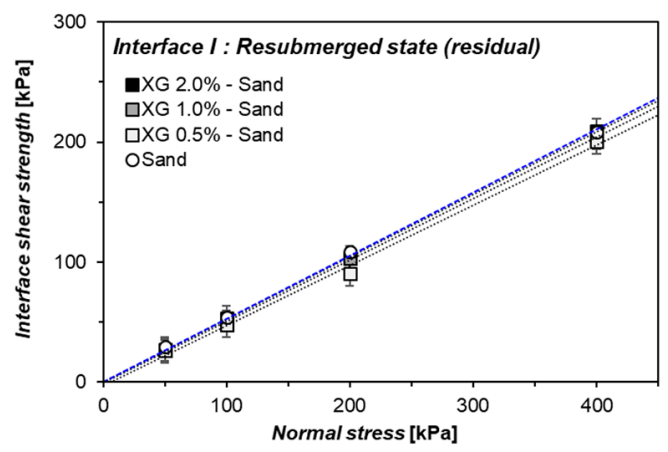

(f)

Figure 8. Peak and residual strengths of xanthan gum-treated sand shearing at interface without asperities (Interface I): (a,b) initial condition; (c,d) dry condition; (e,f) resubmerged condition.

Dehydrated xanthan gum-treated sand at interface I shows an increase in $\delta$ as well as $\mathrm{c}_{\mathrm{a}}$ (i.e., $28.6^{\circ}$ to $35.1^{\circ}$ and $3.2 \mathrm{kPa}$ to $21.5 \mathrm{kPa}$, respectively) with a sequential increase of $M_{X G} / M_{S}$, which is consistent with the general behavior of shearing inside xanthan gum-treated sand, but with a lower strengthening effect (Figure 8c). In the residual state after the peak, a low $c_{a}$ value is reported, and $\delta$ is also reduced but still higher than that of untreated sand (Figure 8d). The interfacial strength mobilized previously in the dried xanthan gum-treated sand was dissipated after the subsequent wetting process and returned to the initial state (Figure $8 \mathrm{e}, \mathrm{f})$. 
Table 5. Mohr-Coulomb failure parameters determined from linear regression (Interface I).

\begin{tabular}{|c|c|c|c|c|c|}
\hline \multirow[b]{2}{*}{ Hydrogel State } & \multirow[b]{2}{*}{$M_{X G} / M_{S}[\%]$} & \multicolumn{2}{|c|}{ Peak Strength } & \multicolumn{2}{|c|}{ Residual Strength } \\
\hline & & $\begin{array}{c}\text { Adhesion } \\
{[\mathrm{kPa}]}\end{array}$ & $\begin{array}{c}\text { Interface Friction } \\
\text { Angle }\left[{ }^{\circ}\right]\end{array}$ & $\begin{array}{c}\text { Adhesion } \\
{[\mathrm{kPa}]}\end{array}$ & $\begin{array}{c}\text { Interface Friction } \\
\text { Angle }\left[{ }^{\circ}\right]\end{array}$ \\
\hline \multirow{4}{*}{ Initial } & 0.0 & 3.1 & 28.6 & 4.1 & 27.1 \\
\hline & 0.5 & $<1$ & 26.610 & $<1$ & 26.1 \\
\hline & 1.0 & 2.2 & 26.3 & 2.2 & 26.3 \\
\hline & 2.0 & $<1$ & 26.7 & 1.2 & 26.6 \\
\hline \multirow{4}{*}{ Dried $^{(1)}$} & 0.0 & 3.2 & 28.6 & $<1$ & 28.3 \\
\hline & 0.5 & 7.1 & 30.1 & $<1$ & 28.7 \\
\hline & 1.0 & 15.1 & 30.7 & 3.1 & 29.6 \\
\hline & 2.0 & 21.5 & 35.1 & $<1$ & 32.8 \\
\hline \multirow{4}{*}{ Resubmerged ${ }^{(2)}$} & 0.0 & 3.1 & 28.6 & 4.1 & 27.1 \\
\hline & 0.5 & $<1$ & 28.3 & $<1$ & 26.6 \\
\hline & 1.0 & 2.8 & 26.9 & 2.3 & 27.0 \\
\hline & 2.0 & 2.0 & 27.6 & $<1$ & 27.5 \\
\hline
\end{tabular}

${ }^{(1)}$ Initial to dried (tested after oven-drying for 21 days at $\left.40{ }^{\circ} \mathrm{C}\right),(2)$ Tested after resubmerging dried specimens for $24 \mathrm{~h}$ at room temperature.

\subsection{Xanthan Gum-Treated Sand Shearing at Interface with Singular Asperity}

For the shearing at interface having a singular asperity (Interfaces II, III, and IV), both the sliding behavior along the flat surface (i.e., $2 / 3 \mathrm{rd}$ of the total interface length) and shear failure inside the soil located in the asperity occur simultaneously. Inevitably, the interface shear stress mobilized at the interface containing the asperity is higher than that at the interface without any asperity. Figure 9 presents the interface shear results at interfaces II, III, and IV, which include one triangular groove with slope angles of $10^{\circ}, 20^{\circ}$, and $30^{\circ}$, respectively.

The $\tau_{i}-\delta$ curve indicates that the peak $\tau_{i}$ increases with higher confinement pressures due to the stronger interlocking among sand grains as well as between sand grains and xanthan gum (Figure 9a). Moreover, $\varepsilon_{v}-\delta$ curves show that the xanthan gum-treated soil turns out to be contractive (i.e., $\psi_{\max }$ decrease from $13^{\circ}$ to $4^{\circ}$ ) as the vertical confinement increases at interface IV. It was found that degree of dilation was distributed within the range between interface I and direct shear test under equivalent $M_{X G} / M_{S}$ and moisture content conditions (Figure 9b).

As shown in Figure $9 c, d$, the change of the moisture state from initially wet to a dehydrated state attributes a noticeable strain softening behavior with increase of the dilation angle. Since the initial state of xanthan gum-treated sand does not show any striking difference in strength according to the $M_{X G} / M_{S}$, the variation in peak $\tau_{i}$ according to the geometry of asperity is also inconspicuous. However, as dehydration occurs, a marked peak $\tau_{i}$ difference according to the asperity dimension was observed, and the post-peak $\tau_{i}$ converged to the same level after failure occurred. Figure $9 \mathrm{f}$ shows the dilation behavior of $1 \%$ xanthan gum-treated sand at all interfaces at the $400 \mathrm{kPa}$ confinement pressure. The difference in the $\psi_{\max }$ according to asperity dimension becomes less sensitive with higher confinement pressures, whereas it is more clearly observed at a low confining pressure $(50 \mathrm{kPa})$.

Figures 10 and 11 present the peak and residual interfacial shear strengths at all interfaces, respectively, and compare them with corresponding shear strengths obtained from soil-soil shearing tests. Figure 10 shows that the Mohr-Coulomb failure envelopes of interfaces II, III, and IV lie below that of xanthan gum-treated soil-soil shearing, but above the failure envelope of interface I. This indicates that the shear strength at the interface with asperity (II, III, and IV) is weaker than the direct shear when failure occurs inside soil. However, the shearing resistance is stronger than the slip-shear behavior of the interface (I) without any influential asperity (i.e., relatively smooth considering the particle size). 


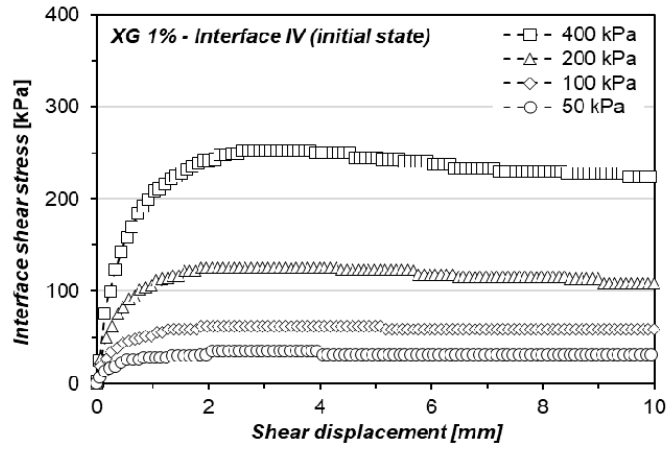

(a)

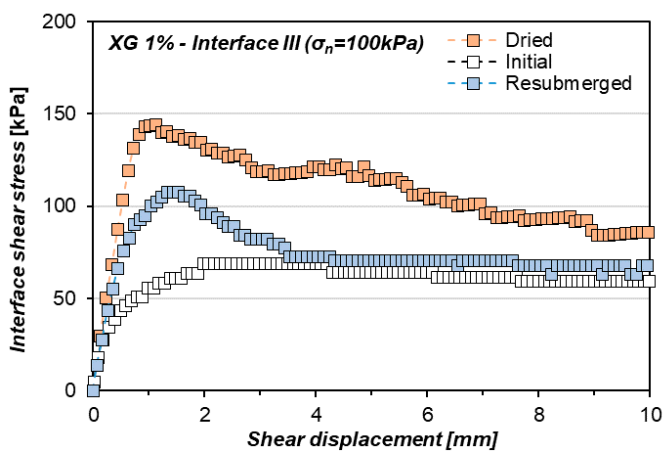

(c)

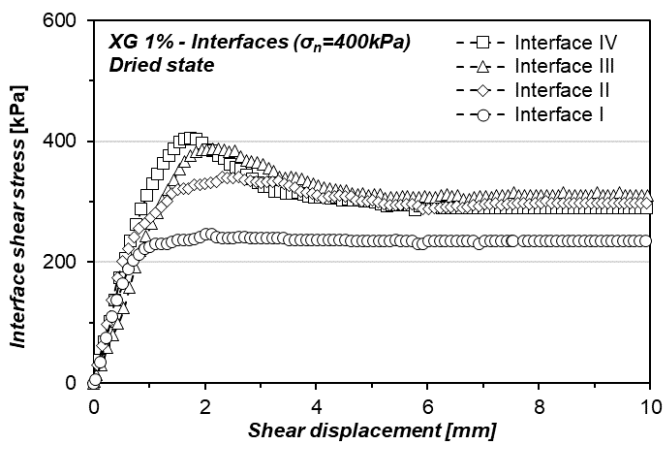

(e)

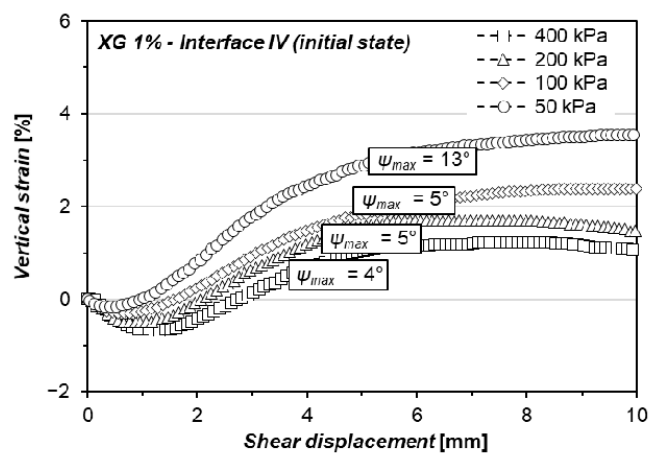

(b)

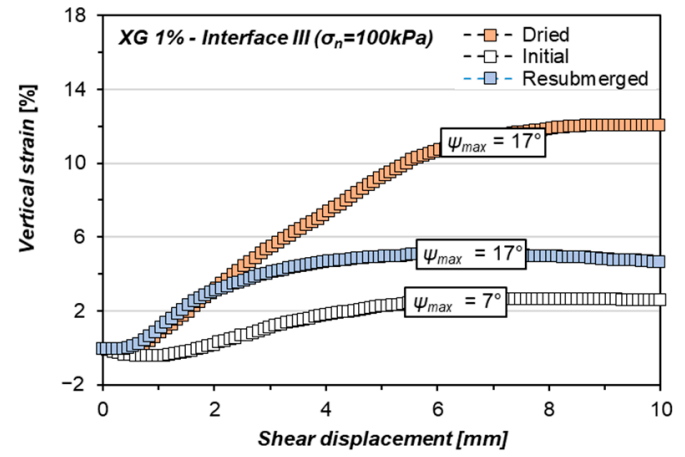

(d)

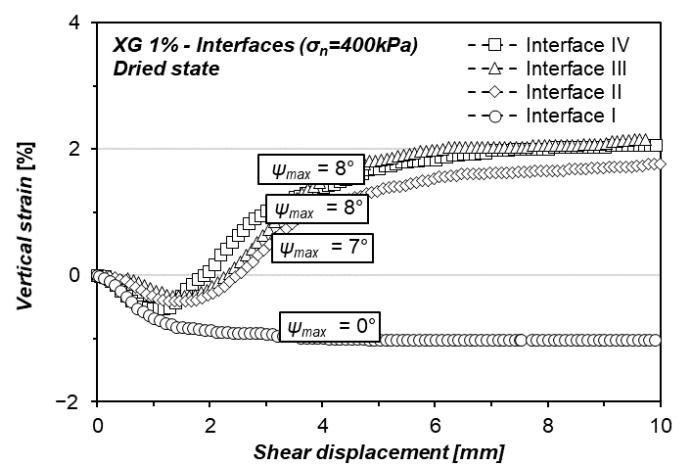

(f)

Figure 9. Interfacial shear test results of xanthan gum-treated soil shearing including asperity (interfaces II, III, IV): (a,c,e) interface shear stress $(\tau)$-horizontal shear displacement $(\delta)$ curves; $(\mathbf{b}, \mathbf{d}, \mathbf{f})$ vertical strain $\left(\varepsilon_{v}\right)$-horizontal shear displacement $(\delta)$ curves.

According to the moisture conditions of xanthan gum, the results of shear failure according to the slope angle of asperity were different under all $M_{X G} / M_{S}$ conditions. When the xanthan gum remained in a hydrogel state, the effect of the asperity dimension did not appear remarkably; in contrast, a distinct variation along the slope angle is seen in the dried state. 

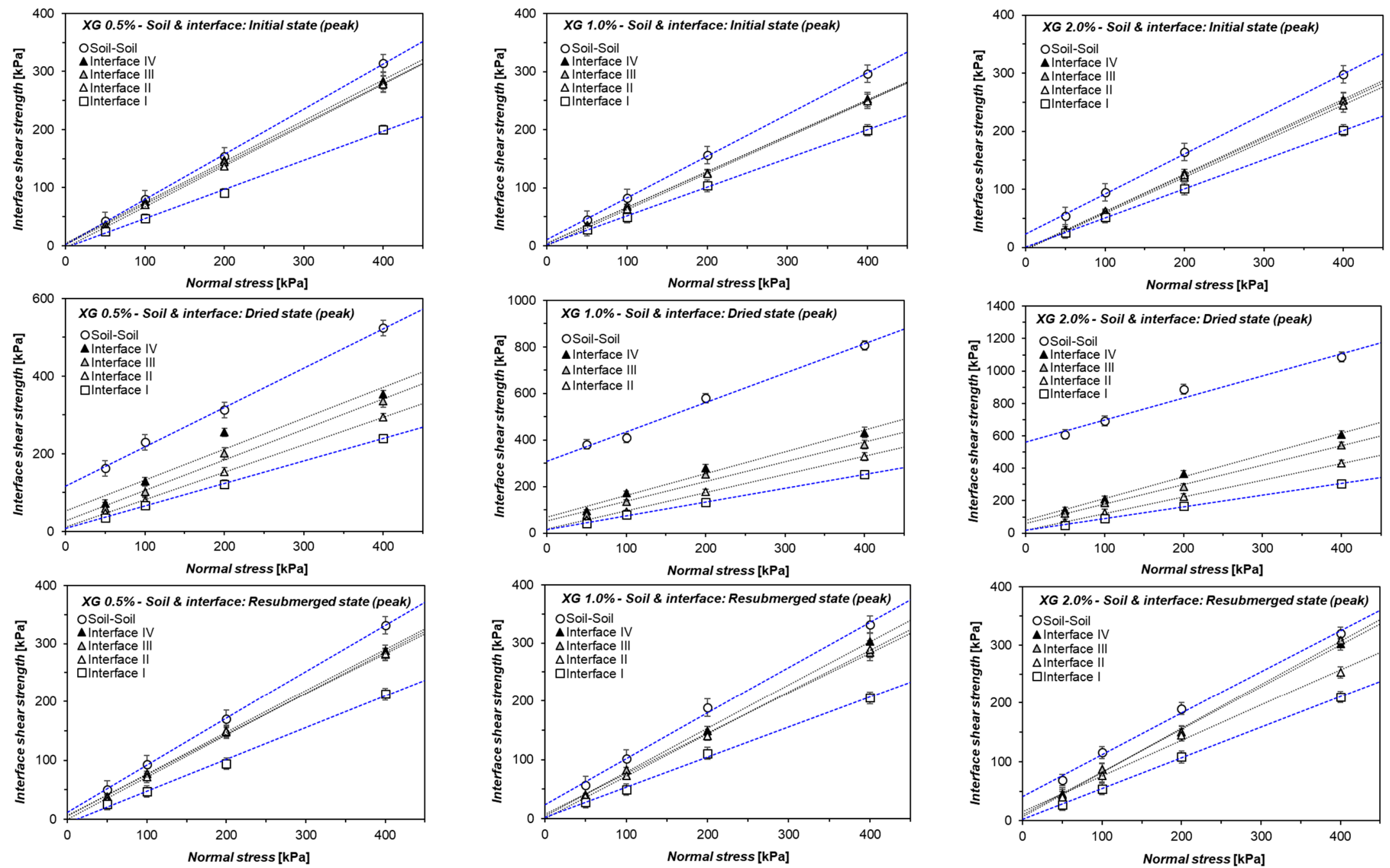

Figure 10. Peak strengths of xanthan gum-treated sand obtained from direct and interfacial shear tests. 

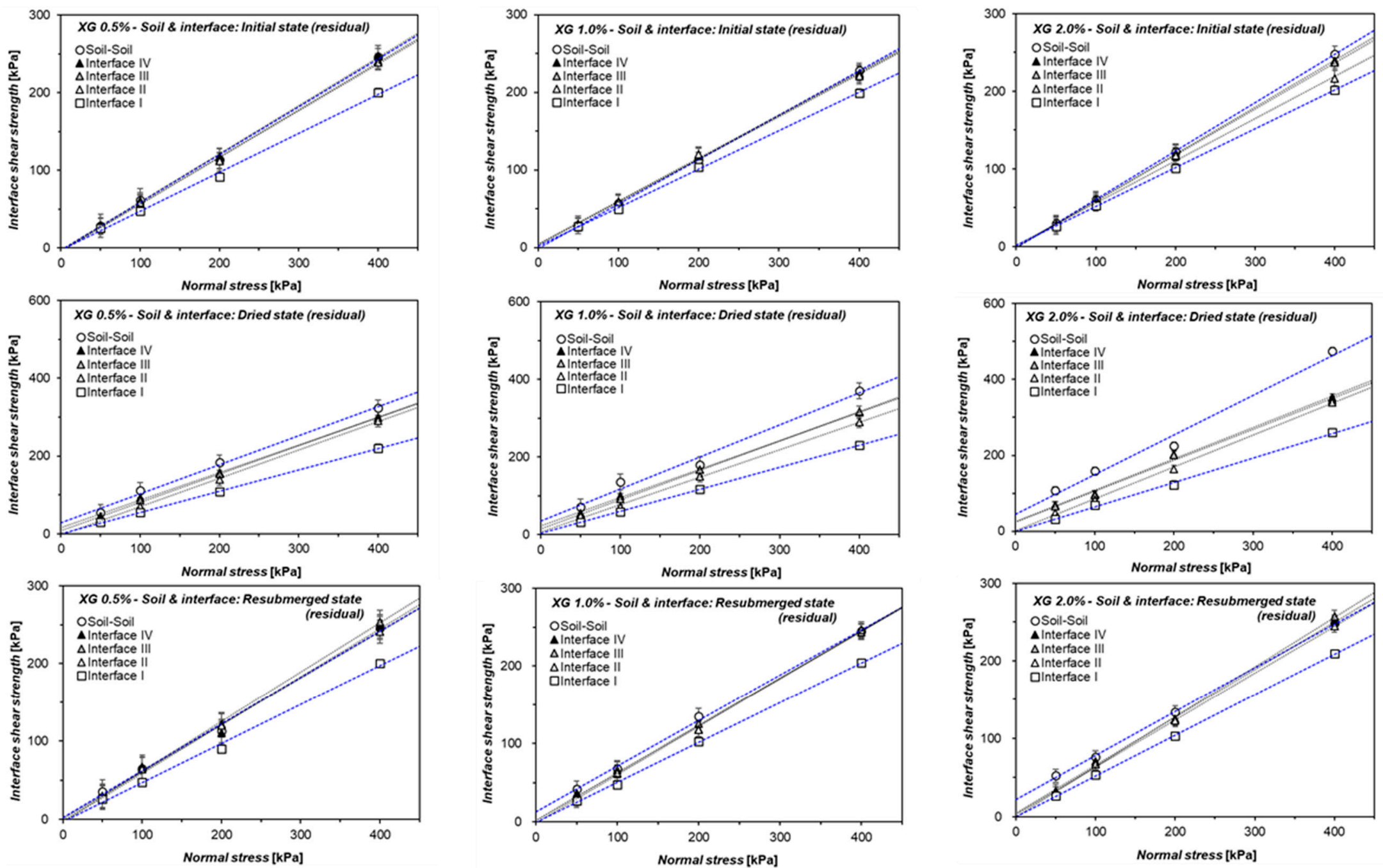

Figure 11. Residual strengths of xanthan gum-treated sand obtained from direct and interfacial shear tests. 
Xanthan gum-treated sand at both wet initial state and resubmerged state shows low cohesion because of the low viscosity of xanthan gum hydrogels (i.e., low $M_{x g} / M_{w}$ ). Thus, the interface interaction and failure between xanthan gum-treated sand and the structural member are regarded to be mostly affected by the relatively weaker xanthan gum-sand medium inside the asperity. Meanwhile, xanthan gum-treated sand at the dried state has distinctively large cohesion due to the high elastic tensile strength of dehydrated (i.e., high $M_{x g} / M_{w}$ ) xanthan gum biofilms forming a continuous matrix among granular particles [16,18]. Highly condensed xanthan gum biofilms can exist as remaining particle coats or viscous fragments in intergranular pore spaces even after the shear failure $[18,21]$, where this can be the possible reason why dried cases show residual adhesion with $M_{X G} / M_{S}$ increase as listed in Table 6.

Under the resubmerged condition, the strength induced in the previously dried state was not fully dissipated upon wetting at high $M_{X G} / M_{S}$ conditions (1\% and $\left.2 \%\right)$. Meanwhile, the strength dropped to its initial state at a low $M_{X G} / M_{S}(0.5 \%)$ because sufficient dissolution and diffusion of xanthan hydrogel occurred. On the contrary, the shear failure envelopes of the residual state were similar to those of soil-to-soil shearing at the initial and resubmerged states as seen from Figure 11. Moreover, there is little difference caused by the asperity condition in the dried state.

Table 6. Mohr-Coulomb failure parameters determined from linear regression (interface II, III, and IV).

\begin{tabular}{|c|c|c|c|c|c|c|}
\hline \multirow[b]{2}{*}{ Interface } & \multirow[b]{2}{*}{ Hydrogel State } & \multirow[b]{2}{*}{$M_{X G} / M_{S}[\%]$} & \multicolumn{2}{|c|}{ Peak Strength } & \multicolumn{2}{|c|}{ Residual Strength } \\
\hline & & & $\begin{array}{c}\text { Adhesion } \\
{[\mathrm{kPa}]}\end{array}$ & $\begin{array}{c}\text { Interface Friction } \\
\text { Angle }\left[{ }^{\circ}\right]\end{array}$ & $\begin{array}{c}\text { Adhesion } \\
{[\mathrm{kPa}]}\end{array}$ & $\begin{array}{c}\text { Interface Friction } \\
\text { Angle }\left[{ }^{\circ}\right]\end{array}$ \\
\hline \multirow{12}{*}{ Interface II } & \multirow{4}{*}{ Initial } & 0.0 & 3.8 & 34.3 & 0.2 & 32.2 \\
\hline & & 0.5 & $<1$ & 33.4 & $<1$ & 30.5 \\
\hline & & 1.0 & $<1$ & 31.9 & 4.0 & 28.7 \\
\hline & & 2.0 & 3.0 & 31.9 & 1.7 & 28.5 \\
\hline & \multirow{4}{*}{ Dried } & 0.0 & 2.6 & 34.3 & $<1$ & 29.7 \\
\hline & & 0.5 & 10.5 & 35.4 & $<1$ & 35.7 \\
\hline & & 1.0 & 17.6 & 38.0 & 7.4 & 35.3 \\
\hline & & 2.0 & 28.7 & 45.9 & 7.1 & 39.4 \\
\hline & \multirow{4}{*}{ Resubmerged } & 0.0 & 3.8 & 34.3 & $<1$ & 32.2 \\
\hline & & 0.5 & $<1$ & 35.4 & 1.3 & 30.9 \\
\hline & & 1.0 & $<1$ & 35.7 & $<1$ & 31.5 \\
\hline & & 2.0 & 6.0 & 31.1 & 2.8 & 31.2 \\
\hline \multirow{12}{*}{ Interface III } & \multirow{4}{*}{ Initial } & 0.0 & 6.5 & 35.5 & 1.6 & 32.4 \\
\hline & & 0.5 & 2.3 & 33.6 & $<1$ & 30.7 \\
\hline & & 1.0 & 2.8 & 31.7 & 4.1 & 29.0 \\
\hline & & 2.0 & 2.0 & 32.4 & 0.5 & 30.6 \\
\hline & \multirow{4}{*}{ Dried } & 0.0 & 1.8 & 35.5 & 4.2 & 29.7 \\
\hline & & 0.5 & 26.6 & 38.2 & 7.9 & 36.1 \\
\hline & & 1.0 & 52.2 & 40.4 & 15.1 & 37.0 \\
\hline & & 2.0 & 59.0 & 50.2 & 23.8 & 39.2 \\
\hline & \multirow{4}{*}{ Resubmerged } & 0.0 & 6.5 & 35.5 & 1.6 & 32.4 \\
\hline & & 0.5 & 6.6 & 34.6 & $<1$ & 32.5 \\
\hline & & 1.0 & 7.2 & 34.5 & $<1$ & 31.2 \\
\hline & & 2.0 & 6.9 & 36.8 & $<1$ & 32.6 \\
\hline \multirow{12}{*}{ Interface IV } & \multirow{4}{*}{ Initial } & 0.0 & 2.3 & 36.7 & $<1$ & 32.8 \\
\hline & & 0.5 & 4.0 & 32.6 & $<1$ & 31.4 \\
\hline & & 1.0 & 1.5 & 32.0 & 4.6 & 28.8 \\
\hline & & 2.0 & 2.5 & 32.8 & 2.6 & 30.9 \\
\hline & \multirow{4}{*}{ Dried } & 0.0 & 2.0 & 36.7 & 6.6 & 29.8 \\
\hline & & 0.5 & 53.2 & 38.5 & 15.1 & 35.4 \\
\hline & & 1.0 & 68.6 & 43.2 & 22.3 & 36.2 \\
\hline & & 2.0 & 80.0 & 53.3 & 25.2 & 39.6 \\
\hline & \multirow{4}{*}{ Resubmerged } & 0.0 & 2.3 & 36.7 & $<1$ & 32.8 \\
\hline & & 0.5 & 5.3 & 35.4 & $<1$ & 31.8 \\
\hline & & 1.0 & 4.5 & 36.6 & 2.0 & 31.2 \\
\hline & & 2.0 & 10.1 & 35.9 & 4.7 & 31.5 \\
\hline
\end{tabular}




\section{Discussion}

\subsection{Effect of Moisture Phase and Concentration of Hydrogel on the Interfacial} Shearing Performance

Generally, the shear behavior of cohesionless sand is dominantly governed by the inter-particle friction [43]. In this study, a wide range of experimental laboratory results showed that the effect of xanthan gum treatment on the internal and interfacial shearing performances was positive. Xanthan gum hydrogel exists as a viscous fluid in the static condition but exhibits a shear-thinning phenomenon where its viscosity decreases when a strain occurs. Thus, xanthan gum treatment provides an artificial force for mitigating the sand particle movement in the static state. However, its effect on the shearing behavior varies depending on the moisture state and $M_{X G} / M_{S}$. Figure 12 presents the internal shear parameters $(\phi$ and $c$ ) of xanthan gum-treated sand.

When xanthan gum treatment in the hydrogel state was performed (i.e., 'initially wet' or 're-wetting after dried'), the cohesion was seen to enhance with $M_{X G} / M_{S}$ increase (Figure 12b); however, the friction angle was rather diminished owing to a decline in the surface dilatancy of sand particles, which was interrupted by the viscous xanthan gum hydrogel occupying the pores (Figure 12a) [18].

The phase of xanthan gum solution changes from the hydrogel to the film state at the critical water content condition. After this phase transformation, xanthan gum gains a tensile strength, which increases the friction angle as well as the cohesion in the dried state. Thus, the effect of $M_{X G} / M_{S}$ on strengthening is much greater in the dried state than in other wet states. The result of internal shear parameters obtained in this study tends to coincide with those of xanthan gum-treated Sydney sand performed in triaxial compression tests [18]. However, the friction angle in the dried state in this study is higher owing to the larger mean particle size and angularity.

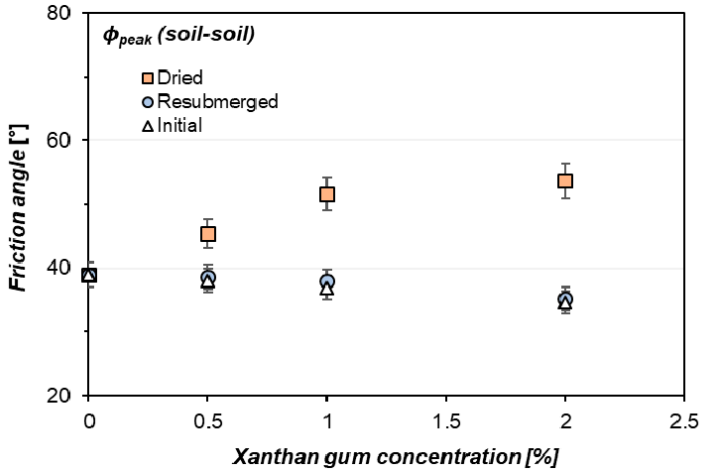

(a)

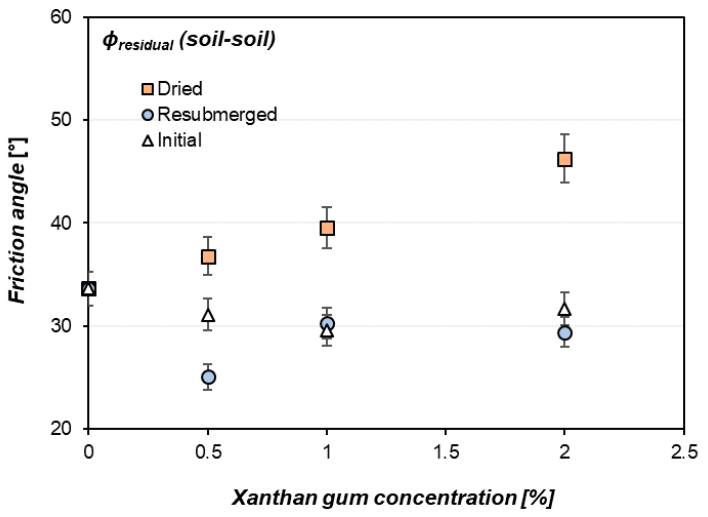

(c)

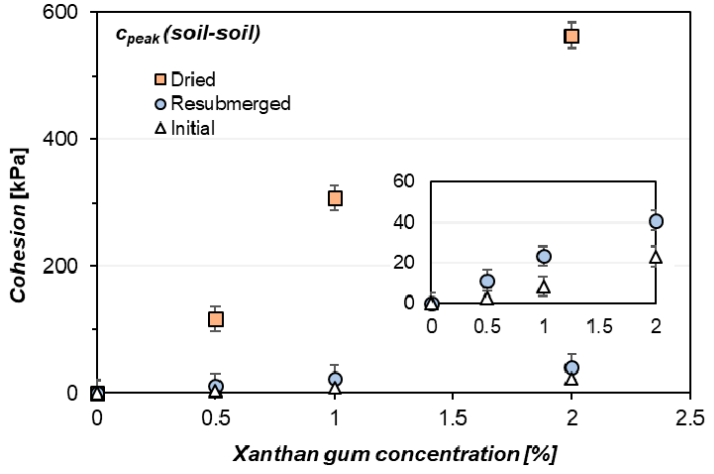

(b)

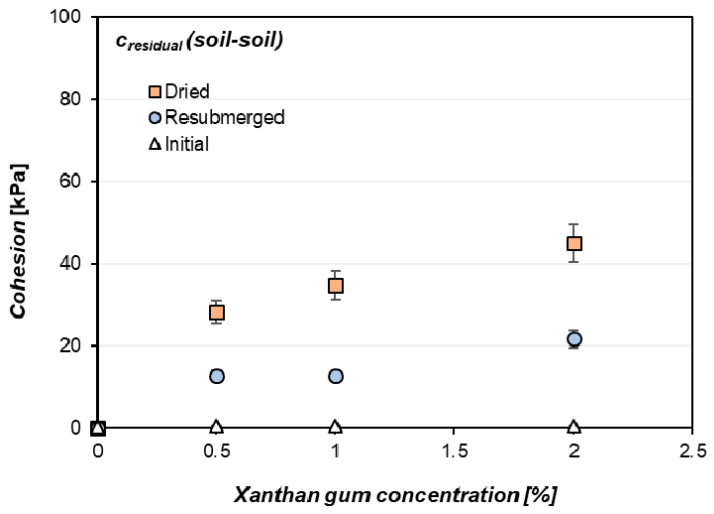

(d)

Figure 12. Internal shear parameters of xanthan gum-treated sand (soil-soil shearing): (a) peak internal friction angle $\left(\phi_{\text {peak }}\right)$, (b) peak cohesion $\left(c_{\text {peak }}\right)$, (c) residual internal friction angle $\left(\phi_{\text {residual }}\right)$, and $(\mathbf{d})$ residual cohesion $\left(c_{\text {residual }}\right)$. 
The effect of xanthan gum treatment on soil-to-soil shearing (direct shear test) also plays a key role in the interfacial shear behavior of xanthan gum-treated sand. The interface friction angle is found to be slightly diminished in the wet state (i.e., initial and resubmerged condition) (Figure 13a,e) and decrease of $\phi$ in soil-to-soil shearing is responsible for the reduction of $\delta$ at interfaces II, III, and IV containing asperity. At these interfaces, not only the failure of soil, but also the sliding shear behavior of interface I is seen. At the sliding occurring interface (I), the shear thinning of xanthan gum hydrogel provides a lubrication effect at low confinement pressures. Therefore, each decrease of $\delta$ in interface II, III, and IV is triggered by the aforementioned two factors. Meanwhile, $\delta$ at interface II, III, and IV is less sensitive with regard to the inclined angle in asperity slope throughout the peak and residual stages (Figures 13a and 14a). Because xanthan gum hydrogel in the initial state and re-swollen xanthan gum in the resubmerged state have a similar shear failure plane which approximates the boundary line regardless of the $M_{X G} / M_{S}$ and asperity slope angle. In addition, $c_{a}$ was not meaningfully affected by $M_{X G} / M_{S}$ or asperity dimension (Figure 13b,f), except in the dried state.

As explained above, $\phi$ inside soil increases when xanthan gum experiences a gel phase transformation due to dehydration. In addition, an elastic tensile film bridge between the sand-xanthan gum mixture and structural surface is formed, thereby providing an additional adhesive force (Figure 13d). Thus, an increase in $\delta$ as well as $c_{a}$ is observed. This strengthening effect increases the stiffness of the soil, and additional friction is generated in the contact area with the asperity slope before failure occurs. Especially at low confinement pressures, the up-shifting force into a direction parallel to the incline is generated, which results in a different failure plane by inclined angle and $M_{X G} / M_{S}$. Hence, the shear performance varies according to the asperity dimension. $c_{a}$ has similar trend to $\delta$ and, in addition, a less remarkable difference according to the asperity dimension and $M_{X G} / M_{S}$ in residual state is seen except for the residual $c_{a}$ in the dried state (Figure 14).

The shear behavior at the interface between the xanthan gum-treated soil and the solid surface shows a moisture content-dependent characteristic. From the viewpoint of geotechnical engineering, reduction in the friction between treated soil and interface due to the lubrication effect of xanthan gum hydrogel can potentially contribute a pressing effect in construction of pile. Thus, xanthan gum treatment can impart a noticeable strength and provide a stability enhancement of the surrounding ground when it loses moisture after construction.

\subsection{Relationship between Internal and Interface Friction Angle of Xanthan Gum-Treated Sand}

In geotechnical engineering practice, it is common to express the interface friction angle $(\delta)$ in terms of soil internal friction angle $(\phi)$, where the aspect ratios of $\delta / \phi$ and tan $\delta / \tan \phi$ are used to assess the interface shearing between sand and geotechnical interface materials (i.e., steel, concrete, and geosynthetic). For instance, $\tan \delta=(0.6 \sim 1.0) \tan \phi$ for woven and non-woven geotextiles, $\tan \delta=(0.8 \sim 1.0) \tan \phi$ for rough woven geotextiles, and $\tan \delta=0.6 \tan \phi$ for granular soil-solid polymer sheet $[9,44-47]$.

In this study, the interface friction angle of biopolymer-treated sand $\left(D_{50}=0.47 \mathrm{~mm}\right)$ and solid surfaces with a relative roughness $\left(R_{n}\right)$ of 0.12 was obtained under various conditions. Figure 15 presents $\tan \delta / \tan \phi$ aspect ratio of xanthan gum-treated sand obtained from this study. For the interface without asperity, the ratios at peak and postpeak are found to be 0.60 and 0.77 , respectively, which is in accordant to the behavior of geosynthetic reinforced sand. For the interface including asperity, these ratios were 0.84 and 0.93, respectively, which are both higher than the typical range due to the predominant soilsoil failure inside the asperity. Thus, this study provides general trends of interface friction angle variation of xanthan gum-treated sand from plane surface attachment (interface I) to surface asperity embedded conditions (interfaces II IV). However, further considerations are required to adopt this result for quantitative analysis since the actual field material has not been used in this study. 


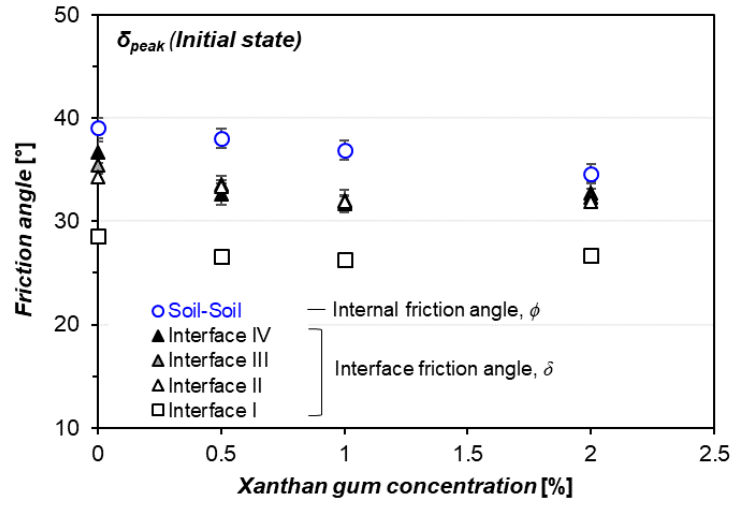

(a)

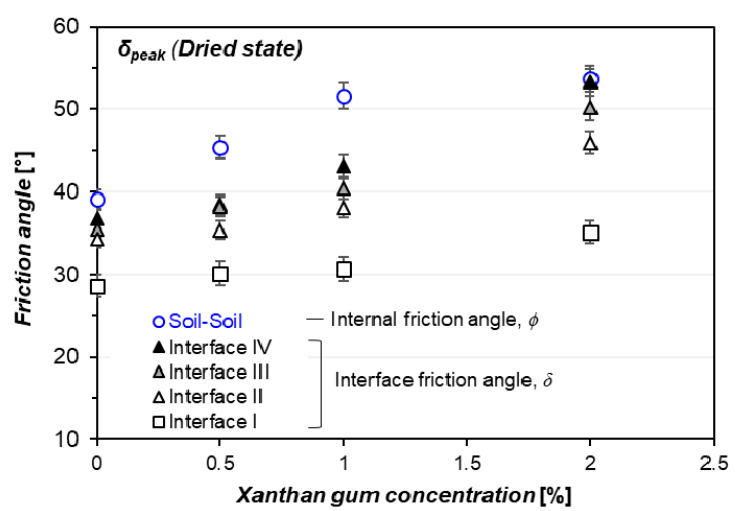

(c)

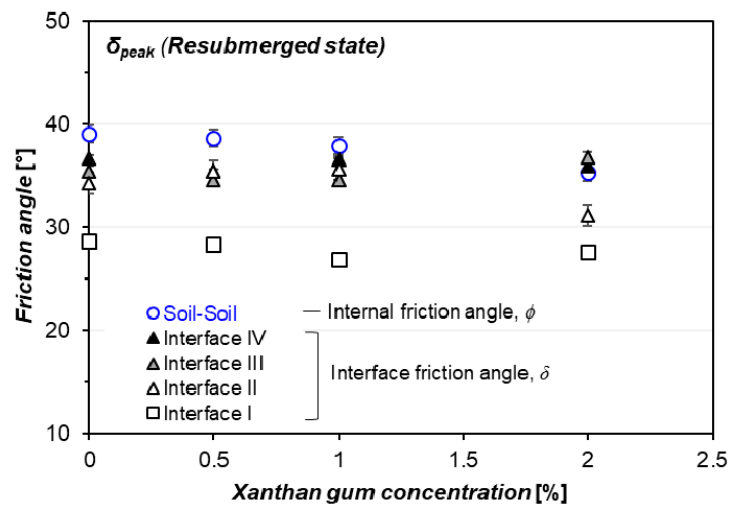

(e)

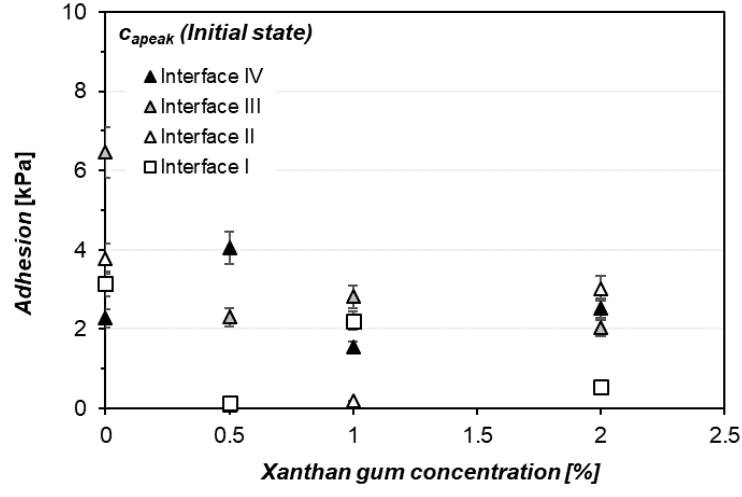

(b)

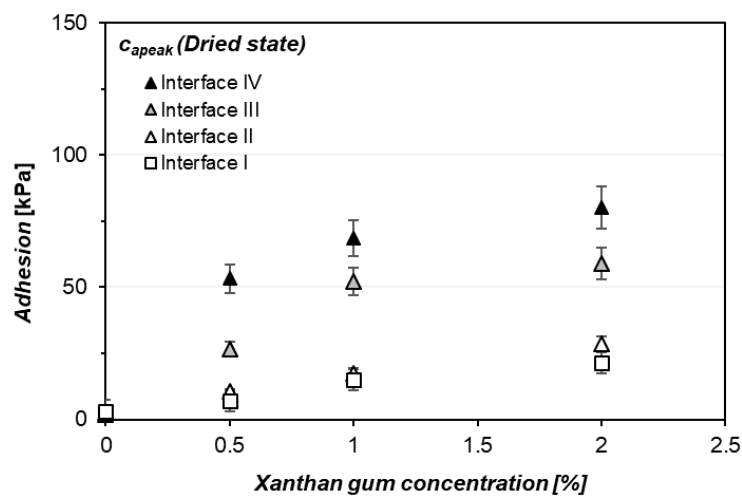

(d)

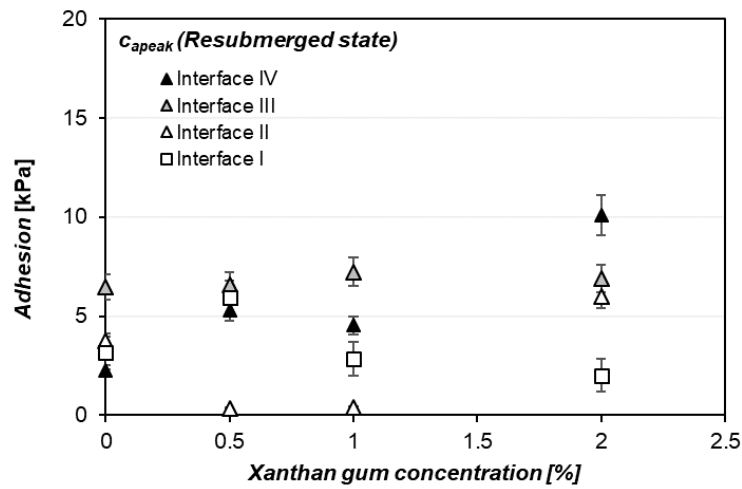

(f)

Figure 13. Peak interfacial shear parameters of xanthan gum-treated sand (soil-structure interface): (a,b) peak interface friction angle $\left(\delta_{\text {peak }}\right)$ and adhesion $\left(c_{\text {apeak }}\right)$ in initial state, $(\mathbf{c}, \mathbf{d})$ peak interface friction angle $\left(\delta_{\text {peak }}\right)$ and adhesion $\left(c_{\text {apeak }}\right)$ in dried state, and $(\mathbf{e}, \mathbf{f})$ peak interface friction angle $\left(\delta_{\text {peak }}\right)$ and adhesion $\left(c_{\text {apeak }}\right)$ in resubmerged state. 


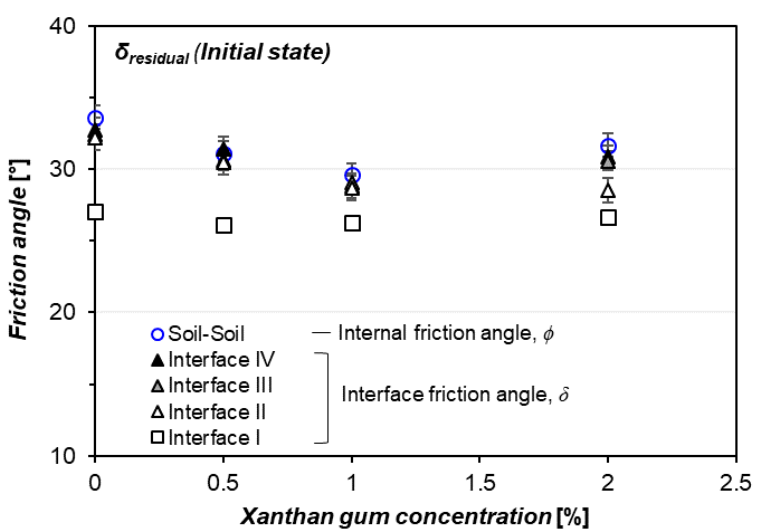

(a)

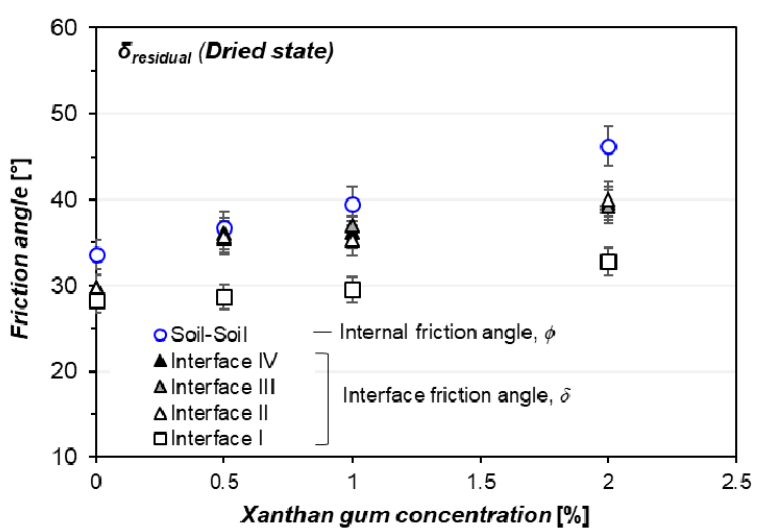

(c)

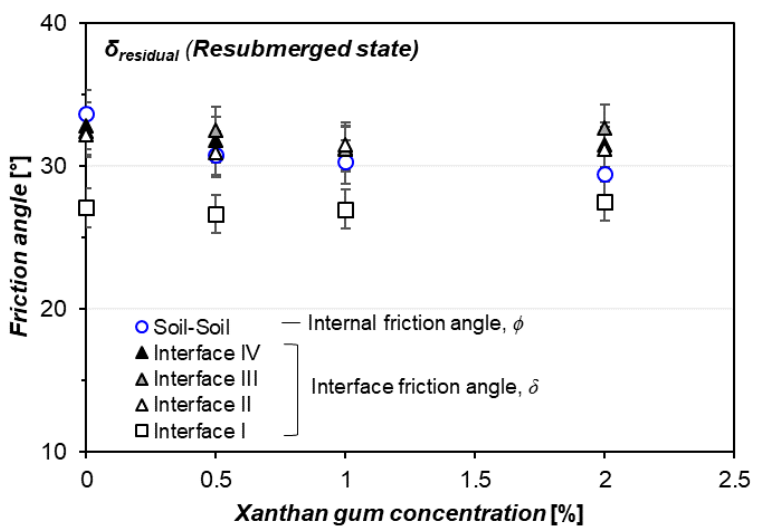

(e)

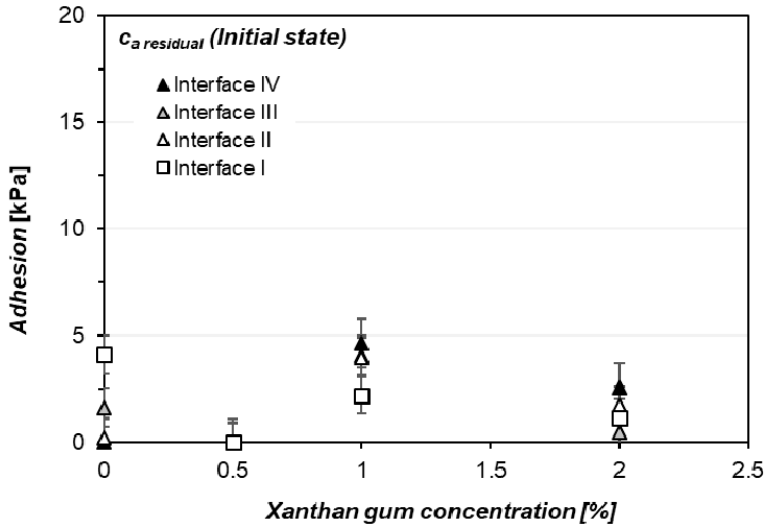

(b)

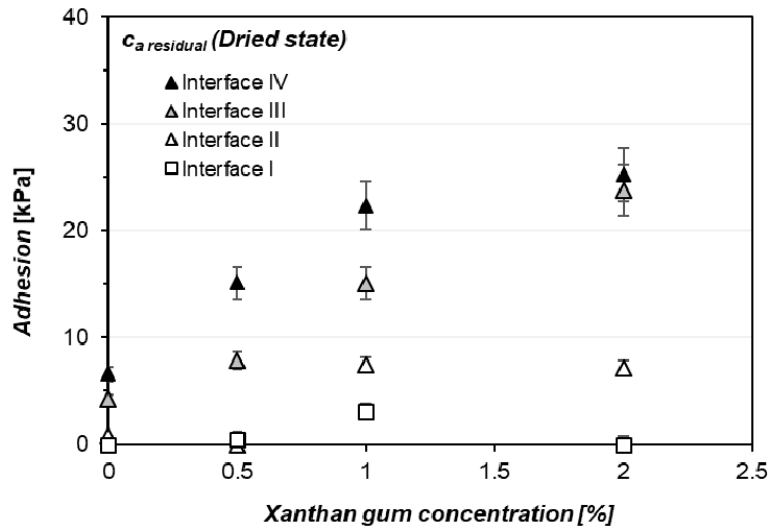

(d)

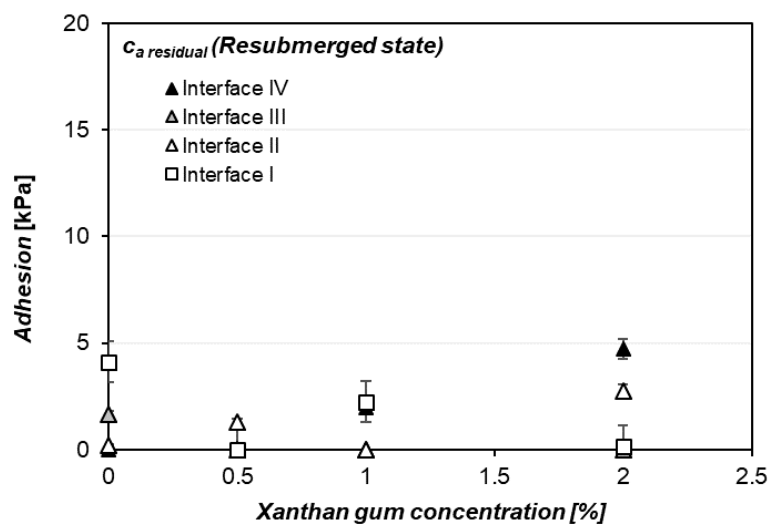

(f)

Figure 14. Residual interfacial shear parameters of xanthan gum-treated sand (soil-structure interface): (a,b) residual interface friction angle $\left(\delta_{\text {residual }}\right)$ and adhesion $\left(c_{\text {aresidual }}\right)$ in initial state, $(\mathbf{c}, \mathbf{d})$ residual interface friction angle $\left(\delta_{\text {residual }}\right)$ and adhesion $\left(c_{\text {aresidual }}\right)$ in dried state, and $(\mathbf{e}, \mathbf{f})$ residual interface friction angle $\left(\delta_{\text {residual }}\right)$ and adhesion $\left(c_{\text {aresidual }}\right)$ in resubmerged state. 

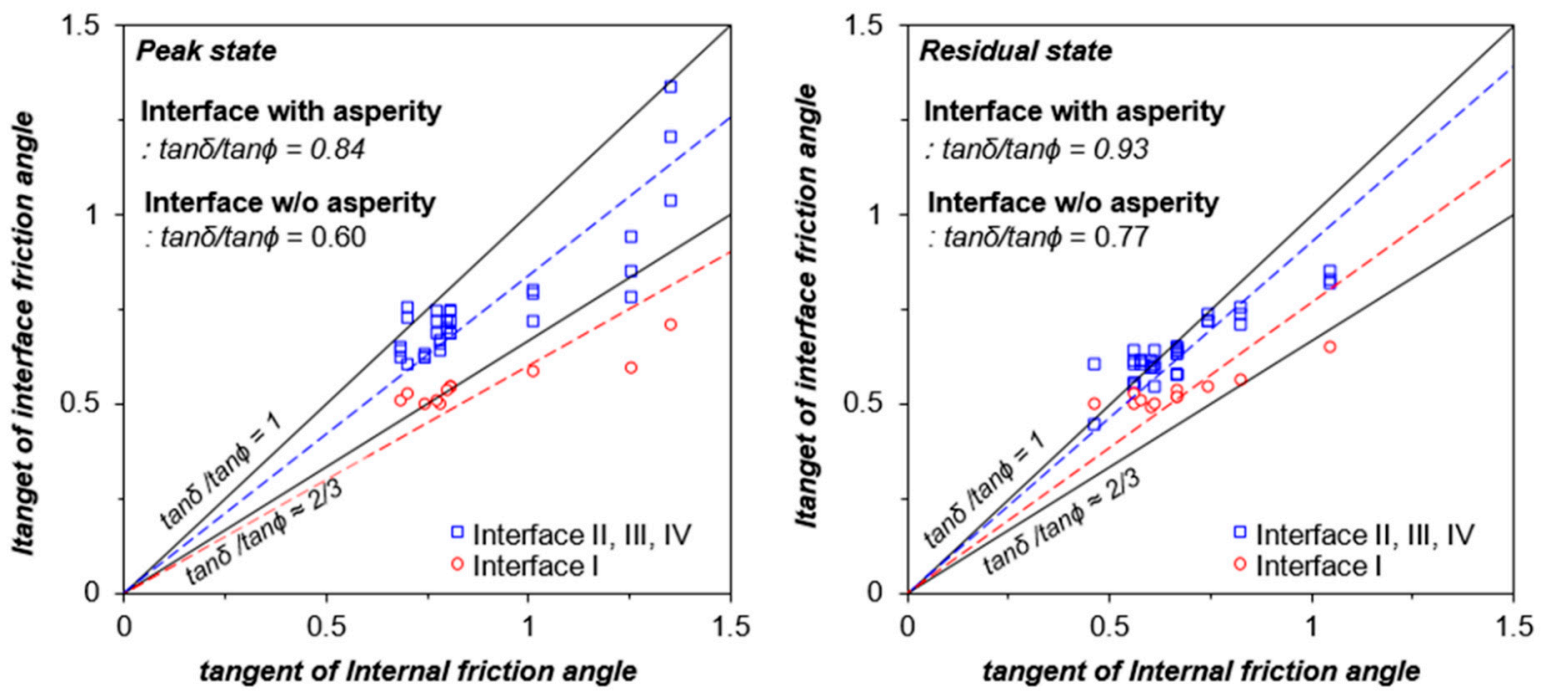

Figure 15. Relationship between internal and interface friction angle of xanthan gum-treated sand.

\section{Conclusions}

In this study, the interface shear test results of xanthan gum-treated soil were compared with those of direct shear (soil-to-soil) tests, and an idea for a geotechnical application was presented by analyzing the relationship between the shear parameters. Xanthan gum-treated sand, which existed in a hydrogel state, showed a slight reduction in the interface friction angle due to the lubricating effect of xanthan gum hydrogel, which exhibits a decrease in viscosity under large strains. However, the strengthening effect was enhanced after the hydrogel phase changed to a film state by dehydration. The interfacial shear strength between the soil particles and surface improved with interfacial shear parameters as the xanthan gum content increased, unlike in the hydrogel state. Therefore, it is expected that the implementation of xanthan gum treatment at the periphery of a shallow foundation (i.e., concrete piles) or press-in type shaft can yield a potential increase in the construction efficiency, considering different effects depending on the moisture state. This may ultimately lead to the improvement in static stability by rendering the near-ground stiff. Meanwhile, this experimental study intended to basically investigate the moisture-dependent effect to the interface shear parameters of xanthan gum-treated sand using a structural element which represents the relative roughness and different asperity conditions. The structure element used in this study is difficult to compensate actual surface friction and hardness of materials used practical implementations, where further considerations are required to adopt obtained results from this study for quantitative analysis and should be carefully compared with on the corresponding behavior of real field materials. Moreover, it needs to be verified using realistic descriptions of the roughness of the actual structural material having large sizes. In addition, further research on the long-term durability of xanthan gum-treated sand as a construction material should also be conducted.

Author Contributions: Conceptualization, M.L., H.H.R. and I.C.; Methodology, M.L. and I.C.; Investigation and Data curation, M.L. and J.I.; Resources, H.H.R.; Writing—original draft preparation, M.L. and I.C.; Writing-review and editing, I.C. and G.-C.C.; Supervision: G.-C.C. and I.C. All authors have read and agreed to the published version of the manuscript.

Funding: The research described in this paper was financially supported by a grant from the Water Management Research Program funded by the Ministry of Land, Infrastructure, and Transport (MOLIT) of the Korean government (20AWMP-B114119-05); and the first author is supported by the Innovated Talent Education Program for Smart City from MOLIT. Also this work was supported by 
the National Research Foundation of Korea (NRF) grant funded by the Korean government (MSIT) (No. 2017R1A5A1014883).

Data Availability Statement: The data presented in this study are available on request from the corresponding author.

Conflicts of Interest: The authors declare no conflict of interest.

\section{References}

1. Han, F.; Ganju, E.; Salgado, R.; Prezzi, M. Effects of interface roughness, particle geometry, and gradation on the sand-steel interface friction angle. J. Geotech. Geoenviron. Eng. 2018, 144, 04018096. [CrossRef]

2. Potyondy, J.G. Skin friction between various soils and construction materials. Geotechnique 1961, 11, 339-353. [CrossRef]

3. Yoshimi, Y.; Kishida, T. A ring torsion apparatus for evaluating friction between soil and metal surfaces. Geotech. Test. J. 1981, 4, 145-152. [CrossRef]

4. Uesugi, M.; Kishida, H.; Tsubakihara, Y. Behavior of sand particles in sand-steel friction. Soils Found. 1988, 28, 107-118. [CrossRef]

5. Dove, J.E.; Frost, J.D. Peak friction behavior of smooth geomembrane-particle interfaces. J. Geotech. Geoenviron. Eng. 1999, 125, 544-555. [CrossRef]

6. Frost, J.; DeJong, J.; Recalde, M. Shear failure behavior of granular-continuum interfaces. Eng. Fract. Mech. 2002, 69, 2029-2048. [CrossRef]

7. Hebeler, G.L. Multi-Scale Behavior at Geomaterial Interfaces. Ph.D. Thesis, Georgia Institute of Technology, Atlanta, GA, USA, 2005.

8. Tinjum, J.; Christensen, R. Site investigation, characterization and assessment for wind turbine design and construction. In Wind Energy Systems; Woodhead Publishing: Cambridge, UK, 2011; pp. 28-45.

9. Das, B.M. Principles of Foundation Engineering, 8th ed.; Cengage Learning: Boston, MA, USA, 2016; 919p.

10. Chang, I.; Lee, M.; Cho, G.-C. Global $\mathrm{CO}_{2}$ emission-related geotechnical engineering hazards and the mission for sustainable geotechnical engineering. Energies 2019, 12, 2567. [CrossRef]

11. Chang, I.; Lee, M.; Tran, A.T.P.; Lee, S.; Kwon, Y.-M.; Im, J.; Cho, G.-C. Review on biopolymer-based soil treatment (BPST) technology in geotechnical engineering practices. Transp. Geotech. 2020, 24, 100385. [CrossRef]

12. Chang, I.; Im, J.; Cho, G.C. Introduction of microbial biopolymers in soil treatment for future environmentally-friendly and sustainable geotechnical engineering. Sustainability 2016, 8, 251. [CrossRef]

13. Chang, I.; Cho, G.-C. Strengthening of Korean residual soil with $\beta-1,3 / 1,6$-glucan biopolymer. Constr. Build. Mater. 2012, 30, 30-35. [CrossRef]

14. Chang, I.; Cho, G.-C. Shear strength behavior and parameters of microbial gellan gum-treated soils: From sand to clay. Acta Geotech. 2019, 14, 361-375. [CrossRef]

15. Cabalar, A.F.; Wiszniewski, M.; Skutnik, Z. Effects of xanthan gum biopolymer on the permeability, odometer, unconfined compressive and triaxial shear behavior of a sand. Soil Mech. Found. Eng. 2017, 54, 356-361. [CrossRef]

16. Chang, I.; Im, J.; Prasidhi, A.K.; Cho, G.-C. Effects of xanthan gum biopolymer on soil strengthening. Constr. Build. Mater. 2015, 74, 65-72. [CrossRef]

17. Chang, I.; Jeon, M.; Cho, G.-C. Application of microbial biopolymers as an alternative construction binder for earth buildings in underdeveloped countries. Int. J. Polym. Sci. 2015, 2015, 326745. [CrossRef]

18. Lee, S.; Im, J.; Cho, G.-C.; Chang, I. Laboratory triaxial test behavior of xanthan gum biopolymer-treated sands. Geomech. Eng. 2019, 17, 445-452. [CrossRef]

19. Tran, A.T.P.; Chang, I.; Cho, G.-C. Wetting soil-water characteristics of xanthan gum biopolymer-treated soils. Can. Geotech. J. 2019. under review.

20. Kwon, Y.-M.; Ham, S.-M.; Kwon, T.-H.; Cho, G.-C.; Chang, I. Surface-erosion behaviour of biopolymer-treated soils assessed by EFA. Géotechnique Lett. 2020, 10, 1-7. [CrossRef]

21. Lee, S.; Chang, I.; Chung, M.-K.; Kim, Y.; Kee, J. Geotechnical shear behavior of xanthan gum biopolymer treated sand from direct shear testing. Geomech. Eng. 2017, 12, 831-847. [CrossRef]

22. Chang, I.; Im, J.; Cho, G.-C. Geotechnical engineering behaviors of gellan gum biopolymer treated sand. Can. Geotech. J. 2016, 53, 1658-1670. [CrossRef]

23. Chen, C.; Wu, L.; Perdjon, M.; Huang, X.; Peng, Y. The drying effect on xanthan gum biopolymer treated sandy soil shear strength. Constr. Build. Mater. 2019, 197, 271-279. [CrossRef]

24. Fatehi, H.; Abtahi, S.M.; Hashemolhosseini, H.; Hejazi, S.M. A novel study on using protein based biopolymers in soil strengthening. Constr. Build. Mater. 2018, 167, 813-821. [CrossRef]

25. Zhong, L.; Oostrom, M.; Truex, M.J.; Vermeul, V.R.; Szecsody, J.E. Rheological behavior of xanthan gum solution related to shear thinning fluid delivery for subsurface remediation. J. Hazard. Mater. 2013, 244, 160-170. [CrossRef] [PubMed]

26. García-Ochoa, F.; Santos, V.; Casas, J.; Gomez, E. Xanthan gum: Production, recovery, and properties. Biotechnol. Adv. 2000, 18, 549-579. [CrossRef]

27. Fowmes, G.J.; Dixon, N.; Fu, L.; Zaharescu, C.A. Rapid prototyping of geosynthetic interfaces: Investigation of peak strength using direct shear tests. Geotext. Geomembr. 2017, 45, 674-687. [CrossRef] 
28. Cislaghi, A.; Sala, P.; Borgonovo, G.; Gandolfi, C.; Bischetti, G.B. Biodegradable Geosynthetics for Geotechnical and Geo-Environmental Engineering; Springer: Cham, Switzerland, 2020; pp. 49-57.

29. Chu, L.-M.; Yin, J.-H. Comparison of interface shear strength of soil nails measured by both direct shear box tests and pullout tests. J. Geotech. Geoenviron. Eng. 2005, 131, 1097-1107. [CrossRef]

30. Kishida, H.; Uesugi, M. Tests of the interface between sand and steel in the simple shear apparatus. Géotechnique 1987, 37, 45-52. [CrossRef]

31. Farhadi, B.; Lashkari, A. Influence of soil inherent anisotropy on behavior of crushed sand-steel interfaces. Soils Found. 2017, 57, 111-125. [CrossRef]

32. Tehrani, F.S.; Han, F.; Salgado, R.; Prezzi, M. Laboratory study of the effect of pile surface roughness on the response of soil and non-displacement piles. Geotech. Front. 2017, 2017, 256-264.

33. Di Donna, A.; Ferrari, A.; Laloui, L. Experimental investigations of the soil-concrete interface: Physical mechanisms, cyclic mobilization, and behaviour at different temperatures. Can. Geotech. J. 2016, 53, 659-672. [CrossRef]

34. Feng, S.-J.; Chen, J.-N.; Chen, H.-X.; Liu, X.; Zhao, T.; Zhou, A. Analysis of sand-woven geotextile interface shear behavior using discrete element method (DEM). Can. Geotech. J. 2020, 57, 433-447. [CrossRef]

35. Lings, M.; Dietz, M. The peak strength of sand-steel interfaces and the role of dilation. Soils Found. 2005, 45, 1-14. [CrossRef]

36. Randolph, M.F. Cyclic interface shearing in sand and cemented soils and application to axial response of piles. In Mechanical Behaviour of Soils under Environmentally Induced Cyclic Loads; Springer: Vienna, Austria, 2012; pp. 481-528.

37. Dove, J.E.; Jarrett, J.B. Behavior of dilative sand interfaces in a geotribology framework. J. Geotech. Geoenviron. Eng. 2002, 128, 25-37. [CrossRef]

38. Wei, X.; Ku, T. New design chart for geotechnical ground improvement: Characterizing cement-stabilized sand. Acta Geotech. 2020, 15, 999-1011. [CrossRef]

39. Wei, X.; Liu, H.; Ku, T. Microscale analysis to characterize effects of water content on the strength of cement-stabilized sand-clay mixtures. Acta Geotech. 2020, 15, 2905-2923. [CrossRef]

40. Chen, C.; Wu, L.; Harbottle, M. Exploring the effect of biopolymers in near-surface soils using xanthan gum-modified sand under shear. Can. Geotech. J. 2019, 1-10. [CrossRef]

41. ASTM. D3080/D3080M-11: Standard Test Method for Direct Shear Test of Soils under Consolidated Drained Conditions; ASTM International: West Conshohocken, PA, USA, 2011. [CrossRef]

42. Stokes, J.R.; Macakova, L.; Chojnicka-Paszun, A.; de Kruif, C.G.; de Jongh, H.H. Lubrication, adsorption, and rheology of aqueous polysaccharide solutions. Langmuir 2011, 27, 3474-3484. [CrossRef] [PubMed]

43. Mitchell, J.K.; Soga, K. Fundamentals of soil Behavior, 3rd ed.; John Wiley \& Sons: Hoboken, NJ, USA, 2005; 577p.

44. Mitchell, J.K.; Villet, W.C. Reinforcement of earth slopes and embankments. Nchrp Rep. 1987, 6, 290.

45. Williams, N.; Houlihan, M. Evaluation of Interface Friction Properties between Geosynthetics and Soils. In Proceedings of the Geosynthetics, New Orleans, LA, USA, 24 February 1987; pp. 616-627.

46. Jewell, R. Soil Reinforcement with Geotextiles; Construction Industry Research and Information Association: London, UK, 1996.

47. Puri, A. The friction coefficient of cohesive soils and geotextile: An approach based on the direct shear test data. Jurnal Saintis 2017, 17, 33-42. 